\title{
Cardiac Autonomic Neuropathy in Obesity, the Metabolic Syndrome and Prediabetes: A Narrative Review
}

\author{
Scott M. Williams (D) A Aikaterini Eleftheriadou - Uazman Alam · \\ Daniel J. Cuthbertson · John P. H. Wilding
}

Received: August 19, 2019 / Published online: September 24, 2019

(C) The Author(s) 2019

\begin{abstract}
Cardiac autonomic neuropathy (CAN) is a major complication of type 1 and type 2 diabetes mellitus (T1DM and T2DM). The increased morbidity, cardiovascular and allcause mortality associated with CAN is established from numerous epidemiological studies. However, CAN is increasingly recognised in people with prediabetes (pre-DM) and the metabolic syndrome (MetS) with a reported prevalence up to $11 \%$ and $24 \%$ respectively. CAN is associated with components of MetS including hypertension and obesity, predating hyperglycaemia. The aetiology of CAN is multifactorial and there is a reciprocal relationship
\end{abstract}

Enhanced Digital Features To view enhanced digital features for this article go to https://doi.org/10.6084/ m9.figshare.9824660.

S. M. Williams ( $\square)$

Leighton Hospital, Middlewich Rd, Crewe, UK

e-mail: scottw@doctors.org.uk

\section{A. Eleftheriadou}

The University of Liverpool School of Medicine,

Cedar House, Ashton Street, Liverpool, UK

U. Alam

Diabetes and Neuropathy Research, Department of Eye and Vision Sciences and Pain Research Institute, Institute of Ageing and Chronic Disease, University of Liverpool and Aintree University Hospital NHS

Foundation Trust, Liverpool, UK with insulin resistance and MetS. Obstructive sleep apnoea (OSA) is also associated with CAN possibly through MetS and an independent mechanism. An estimated global prevalence of the impaired glucose tolerance (IGT) form of pre-DM of 587 million people by 2045 means CAN will become a major clinical problem. CAN is independently associated with silent myocardial ischaemia, major cardiovascular events, myocardial dysfunction and cardiovascular mortality. Screening for CAN in pre-DM using risk scores with analysis of heart rate variability (HRV) or Sudoscan is important to allow earlier treatment at a reversible stage. The link between obesity and CAN highlights the therapeutic potential of lifestyle interventions including diet and physical activity to reverse MetS and prevent CAN. Weight loss achieved using these dietary and exercise lifestyle interventions improves the sympathetic and

U. Alam

Royal Liverpool and Broadgreen University NHS Hospital Trust, Liverpool, UK

\section{U. Alam}

Division of Endocrinology, Diabetes and

Gastroenterology, University of Manchester, Manchester, UK

D. J. Cuthbertson · J. P. H. Wilding

Obesity and Endocrinology Research, Institute of Ageing and Chronic Disease, Faculty of Health and Life Sciences, University of Liverpool, Liverpool, UK 
parasympathetic HRV indices of cardiac autonomic function. Further research is needed to identify high-risk populations of people with pre-DM or obesity that might benefit from targeted pharmacotherapy including metformin, sodium/glucose cotransporter 2 (SGLT2) inhibitors and glucagon-like peptide 1 (GLP-1) analogues. Bariatric surgery also improves HRV through weight loss which might also prevent CAN in severe obesity. This article reviews the literature on CAN in obesity, pre-DM and MetS, to help determine a rationale for screening, early intervention treatment and formulate future research questions in this highly prevalent condition.

Keywords: Cardiac autonomic neuropathy; Lifestyle intervention; Metabolic syndrome; Obesity; Prediabetes

\section{INTRODUCTION}

Diabetic cardiac autonomic neuropathy (CAN) is defined by the Toronto consensus panel as "the impairment of autonomic control of the cardiovascular system in the setting of diabetes after the exclusion of other causes" $[1,2]$. CAN is well recognised as a complication of type 1 and type 2 diabetes mellitus (T1DM and T2DM) but there is growing evidence that CAN also occurs in obesity, pre-DM and the metabolic syndrome (MetS), predating the development of T2DM [2]. The population affected by CAN is therefore likely to grow as the obesity epidemic continues [3-7].

CAN results in pathology to the sympathetic and parasympathetic nerve fibres supplying the heart and blood vessels [8]. The vagus nerve, the longest autonomic nerve, mediates about 75\% of all parasympathetic nervous system (PNS) activity [9]. Because neuropathy occurs in the longest nerve fibres, the earliest manifestations of autonomic neuropathy in diabetes result from PNS denervation and changes in heart rate variability (HRV) [10, 11]. Abnormalities in vascular tone and heart rate control typically including a resting tachycardia then develop in advanced stages. This eventually leads to the failure of normal blood pressure regulation which causes presyncopal symptoms, exercise intolerance, palpitations and syncope. These symptoms cause significant disability and impair quality of life [12]. They reflect the cardiovascular instability of severe CAN and the associated significantly increased risk of cardiovascular mortality [3].

There is a higher proportion of deaths consistent with sudden cardiac death (SCD) in people with CAN and diabetes [8]. CAN is an independent risk factor for increased silent myocardial ischaemia, major cardiovascular events, myocardial dysfunction and cardiovascular mortality $[2,13]$. Ewing et al. showed nearly 30 years ago that the resting QT interval corrected for heart rate (QTc) on an electrocardiogram (ECG) correlates with the stage of development of CAN in patients with diabetes. The study also showed that the resting QTc was longest in individuals who died unexpectedly during follow-up, possibly because of cardiac arrythmias [14]. The ACCORD interventional study in T2DM showed that patients with CAN diagnosed at baseline had a 1.55-2.14 increased relative risk of mortality compared to those without CAN [15]. CAN is associated with a higher prevalence and more severe form of heart failure with preserved ejection fraction (HFpEF) in patients with diabetes, with significant associated mortality $[16,17]$.

More recently the higher prevalence of cardiovascular disease in obese people with normal glucose tolerance (NGT) has been associated with the MetS and autonomic dysfunction [18]. There is a significant association between increasing body mass index (BMI) and an increased risk of CAN [19]. A recent study of people with obesity and NGT has demonstrated that increased waist to hip ratio (WHR) indicating visceral adiposity within this group is associated with impaired PNS and sympathetic nervous system (SNS) control of cardiac autonomic function [18]. This suggested that slight increases in the WHR in obese individuals could increase their risk of cardiovascular morbidity and mortality through CAN [18]. Obesity causes a reduction HRV indices consistent with a reduction in PNS activity that disrupts the normal maturation of cardiac autonomic control in healthy obese children $[20,21]$. 


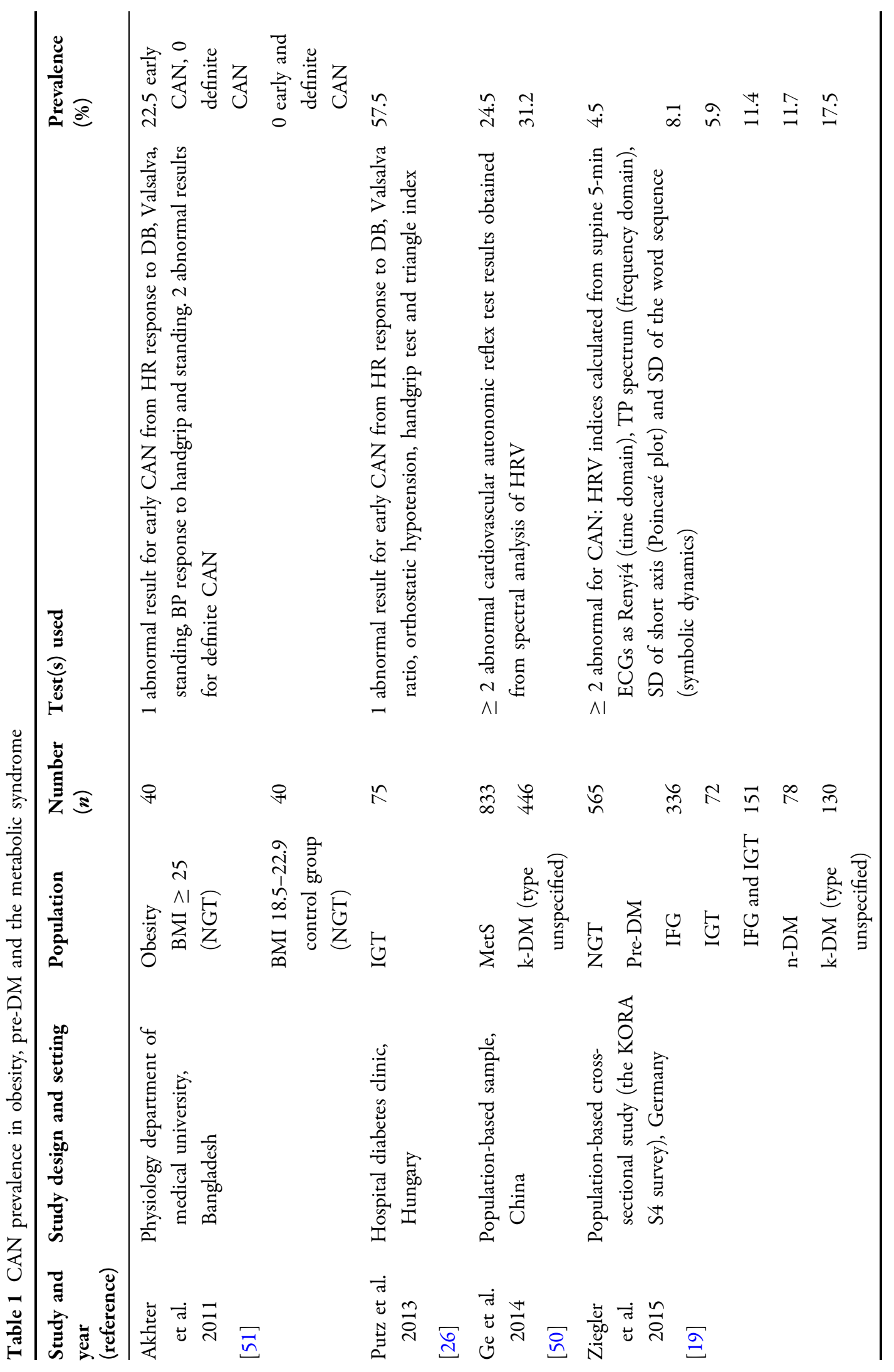




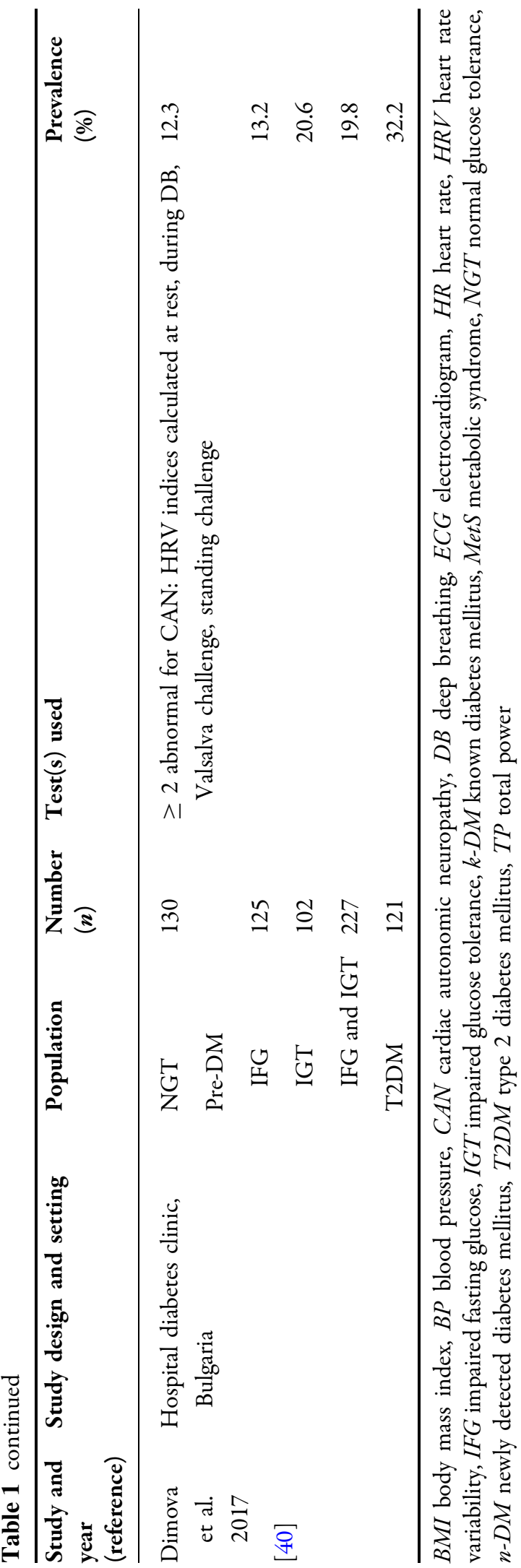

Over the last four decades, advances in diagnostic techniques have facilitated preclinical identification of CAN which may have implications for its reversibility using lifestyle interventions [22, 23]. Obesity, pre-DM and MetS have more recently been associated with CAN [2]. The numbers of patients affected by CAN will greatly increase as the prevalence of pre-DM continues to increase to epidemic proportions. There are an estimated 352.1 million individuals living worldwide with the impaired glucose tolerance (IGT) form of pre-DM $(7.3 \%$ of global adult population). This estimate is expected to rise to 587 million people $(8.3 \%$ of global adult population) by the year 2045 $[24,25]$.

Several studies have shown that the prevalence of CAN is higher in pre-DM and the MetS compared to NGT $[2,13,19,26,27]$. Table 1 is a summary of CAN prevalence studies across obesity, pre-DM and the MetS. Obesity is defined by the World Health Organisation (WHO) as abnormal or excessive fat accumulation that may impair health and is categorised by BMI, an index of weight-for-height [28]. Pre$\mathrm{DM}$ is a collective term for impaired fasting glucose (IFG) and/or IGT. MetS has been defined by the WHO, International Diabetes Federation (IDF) and National Cholesterol Education Program Adult Treatment Panel III (NCEP ATP III). Central obesity can also be defined by waist circumference (WC) and is used in different MetS criteria [29, 30]. A summary of international definitions of obesity, pre-DM and the MetS is shown in Table 2. The increased cardiovascular mortality associated with pre-DM and the MetS may be related to CAN and this requires further research. This article is based on previously conducted studies and does not contain any studies with human participants or animals performed by any of the authors.

\section{EPIDEMIOLOGY OF CAN}

There is considerable discrepancy in the prevalence of CAN reported across populations with diabetes and pre-DM. The use of different definitions, diagnostic tests performed and the study population sampled have resulted in the 
Table 2 Summary of definitions of obesity, pre-DM and metabolic syndrome (MetS)

\begin{tabular}{|c|c|c|c|c|}
\hline Definition, year & WHO, $1998[28,44,75]$ & $\begin{array}{l}\text { NCEP ATP III, } \\
2002[127]\end{array}$ & $\begin{array}{l}\text { ADA, } 2003 \text { [162] IDF, } \\
2005[30]\end{array}$ & $\begin{array}{l}\text { Consensus, } 2009 \\
{[163]}\end{array}$ \\
\hline $\begin{array}{l}\text { IFG } \\
(\text { pre-DM })^{\mathrm{a}}\end{array}$ & FPG $6.1-6.9 \mathrm{mmol} / \mathrm{L}$ & - & $\begin{array}{l}\text { FPG } 5.6 \mathrm{mmol} / \mathrm{L} \text { and } \\
\quad 6.9 \mathrm{mmol} / \mathrm{L}\end{array}$ & - \\
\hline $\begin{array}{l}\text { IGT } \\
(\text { pre-DM })^{\mathrm{a}}\end{array}$ & $\begin{array}{l}\text { OGTT 2-h glucose } \\
7.8 \mathrm{mmol} / \mathrm{L} \text { and } \\
11.0 \mathrm{mmol} / \mathrm{L}\end{array}$ & - & $\begin{array}{l}\text { OGTT 2-h glucose } \\
7.8 \mathrm{mmol} / \mathrm{L} \text { and } \\
11.0 \mathrm{mmol} / \mathrm{L}\end{array}$ & - \\
\hline $\begin{array}{r}\text { MetS essential } \\
\text { requirement }\end{array}$ & $\begin{array}{l}\text { Insulin resistance (IFG, IGT } \\
\text { or other evidence including } \\
\text { euglycaemic clamp studies) } \\
\text { or diabetes }\end{array}$ & $\begin{array}{l}\text { No essential } \\
\text { requirement }\end{array}$ & $\begin{array}{l}\text { Central obesity } \\
\qquad \begin{array}{l}\text { (WC } \geq 94 \mathrm{~cm} \text { (males), } \\
\text { or } 80 \mathrm{~cm} \text { (females) or a } \\
\text { BMI }>30 \mathrm{~kg} / \mathrm{m}^{2} \text { ) }\end{array}\end{array}$ & $\begin{array}{l}\text { No essential } \\
\text { requirement }\end{array}$ \\
\hline MetS criteria & $\begin{array}{l}\text { Insulin resistance or diabetes } \\
\quad \text { and } \geq 2 \text { criteria }\end{array}$ & $\geq 3$ of 5 criteria & Obesity and $\geq 2$ criteria & $\geq 3$ of 5 criteria \\
\hline Obesity in MetS & $\begin{array}{l}\text { A waist to hip ratio } \\
>0.90 \text { (males) or } \\
>0.85 \text { in females or a } \\
\quad \mathrm{BMI}>30 \mathrm{~kg} / \mathrm{m}^{2} \text { (obese) }^{\mathrm{b}}\end{array}$ & $\begin{array}{l}\mathrm{WC}>102 \mathrm{~cm}(40 \\
\text { inches) (males), or } \\
>88 \mathrm{~cm}(35 \\
\text { inches) (females) }\end{array}$ & $\begin{array}{l}\text { Central obesity or a } \\
\text { BMI }>30 \mathrm{~kg} / \mathrm{m}^{2} \text { already } \\
\text { essential, needs another } \\
\text { two or more criteria }\end{array}$ & $\begin{array}{l}\text { Elevated WC } \\
\text { (population and } \\
\text { country-specific } \\
\text { definitions) }\end{array}$ \\
\hline $\begin{array}{l}\text { Hyperglycaemia } \\
\text { in MetS }\end{array}$ & $\begin{array}{l}\text { Already essential, needs } \\
\text { another } \geq 2 \text { criteria }\end{array}$ & $\begin{array}{l}\text { FPG } \\
\begin{array}{c}\geq 6.1 \mathrm{mmol} / \mathrm{L} \\
(110 \mathrm{mg} / \mathrm{dL})\end{array}\end{array}$ & $\begin{array}{l}\text { FPG } \\
\geq 5.6 \mathrm{mmol} / \mathrm{L}(100 \mathrm{mg} / \\
\mathrm{dL})\end{array}$ & $\begin{array}{l}\text { FPG } \\
\begin{array}{c}\geq 5.6 \mathrm{mmol} / \mathrm{L} \\
(100 \mathrm{mg} / \mathrm{dL})\end{array}\end{array}$ \\
\hline $\begin{array}{l}\text { Dyslipidaemia in } \\
\text { MetS }\end{array}$ & $\begin{array}{l}\mathrm{TG} \geq 1.7 \mathrm{mmol} / \mathrm{L} \\
\quad(150 \mathrm{mg} / \mathrm{dL}) \text { or } \mathrm{HDL} \\
\quad \text { cholesterol } \\
<35 \mathrm{mg} / \mathrm{dL} \text { (males) or } \\
<39 \mathrm{mg} / \mathrm{dL} \text { (females) }\end{array}$ & $\begin{array}{l}\mathrm{TG} \geq 1.7 \mathrm{mmol} / \mathrm{L} \\
(150 \mathrm{mg} / \mathrm{dL})\end{array}$ & $\begin{array}{l}\mathrm{TG} \geq 1.7 \mathrm{mmol} / \mathrm{L} \\
(150 \mathrm{mg} / \mathrm{dL})\end{array}$ & $\begin{array}{l}\mathrm{TG} \geq 1.7 \mathrm{mmol} / \\
\mathrm{L}(150 \mathrm{mg} / \mathrm{dL})\end{array}$ \\
\hline $\begin{array}{l}\text { Dyslipidaemia in } \\
\text { MetS second } \\
\text { criteria }\end{array}$ & $\mathrm{N} / \mathrm{A}$ & $\begin{array}{l}\text { HDL cholesterol } \\
<1.04 \mathrm{mmol} / \mathrm{L} \\
\quad(40 \mathrm{mg} / \mathrm{dL}) \text { (males) } \\
\text { or } \\
<1.29 \mathrm{mmol} / \mathrm{L} \\
\quad(50 \mathrm{mg} / \mathrm{dL}) \\
\text { (females) }\end{array}$ & $\begin{array}{l}\text { HDL cholesterol } \\
<1.04 \mathrm{mmol} / \mathrm{L}(40 \mathrm{mg} / \\
\text { dL) (males), or } \\
<1.29 \mathrm{mmol} / \mathrm{L}(50 \mathrm{mg} / \\
\mathrm{dL}) \text { (females) }\end{array}$ & $\begin{array}{l}\text { HDL cholesterol } \\
<1.04 \mathrm{mmol} / \mathrm{L} \\
\quad(40 \mathrm{mg} / \mathrm{dL}) \\
\quad \text { (males) } \text { or } \\
<1.29 \mathrm{mmol} / \mathrm{L} \\
\quad(50 \mathrm{mg} / \mathrm{dL}) \\
\text { (females) }\end{array}$ \\
\hline $\begin{array}{l}\text { Hypertension in } \\
\text { MetS }\end{array}$ & $\mathrm{BP} \geq 140 / 90 \mathrm{mmHg}$ & $\begin{array}{l}\mathrm{BP}>130 \mathrm{mmHg} \\
\quad \text { systolic or } \\
>85 \mathrm{mmHg} \\
\text { diastolic }\end{array}$ & $\begin{array}{l}\mathrm{BP}>130 \mathrm{mmHg} \text { systolic } \\
\quad \text { or } \\
>85 \mathrm{mmHg} \text { diastolic }\end{array}$ & $\begin{array}{l}\mathrm{BP}>130 \mathrm{mmHg} \\
\quad \text { systolic or } \\
>85 \mathrm{mmHg} \\
\text { diastolic }\end{array}$ \\
\hline
\end{tabular}


Table 2 continued

\begin{tabular}{lllll}
\hline Definition, year & WHO, 1998 [28, 44, 75] & $\begin{array}{l}\text { NCEP ATP III, } \\
2002[127]\end{array}$ & $\begin{array}{l}\text { ADA, 2003 [162] IDF, } \\
\text { 2005 [30] }\end{array}$ & $\begin{array}{l}\text { Consensus, 2009 } \\
{[163]}\end{array}$ \\
\hline $\begin{array}{l}\text { MetS further } \\
\text { criteria }\end{array}$ & $\begin{array}{l}\text { Microalbuminuria; a urinary } \\
\text { albumin } \\
\text { excretion } \geq 20 \mu \mathrm{g} / \mathrm{min} \text { or } \\
\text { ACR } \geq 30 \mathrm{mg} / \mathrm{g}\end{array}$ & N/A & N/A \\
\hline
\end{tabular}

$A C R$ albumin creatinine ratio, $A D A$ American Diabetes Association, $B M I$ body mass index, $B P$ blood pressure, $F P G$ fasting plasma glucose, $H D L$ high-density lipoprotein, $I D F$ International Diabetes Federation, $I F G$ impaired fasting glucose, $I G T$ impaired glucose tolerance, $N / A$ not applicable, NCEP ATP III National Cholesterol Education Program Adult Treatment Panel III, OGTT oral glucose tolerance test, $T G$ triglycerides, $W C$ waist circumference, $W H O$ World Health Organisation

${ }^{\text {a }} \mathrm{HbAlc} 5.7-6.4 \%$ (39-47 mmol/mol) may also be used to define pre-DM in the ADA classification [162]

b The WHO definition of obesity is in bold. A BMI of $\geq 25 \mathrm{~kg} / \mathrm{m}^{2}$ has been suggested for an Asian Indian population. WC and waist to hip ratio are used as central obesity criteria in MetS definitions [75, 164]

disparity in prevalence figures [10, 31]. Varying numbers of abnormal autonomic function tests also convey different prognostic information, with a worse prognosis conveyed by a greater number of abnormal results [14]. This increases difficulty in comparing the clinical implications of studies with different definitions of CAN $[14,32]$. Abnormal HRV indices are suggestive of abnormal cardiac autonomic function and represent a surrogate marker of CAN [12].

\section{CAN in Pre-DM and MetS}

To date, ten studies have demonstrated evidence of reduced HRV or abnormal cardiovascular reflex tests in subjects with pre-DM compared to those with NGT. Six of these studies were population-based and four in hospital outpatient clinics involving a range of 56-3561 people with IFG, 25-188 people with IGT and 151 people with IFG-IGT combined. NGT control groups have ranged from 30 to 5410 people $[19,26,33-40]$. There is significant heterogeneity and overlap between studies $[2,19,34]$. One study has considered IFG defined by the 1997 American Diabetes Association (ADA) criteria of fasting plasma glucose (FPG) $\quad 6.1-6.9 \mathrm{mmol} / \mathrm{L}$ compared to NGT $[34,41]$. Six studies have considered IFG defined by the 2003 ADA criteria (FPG 5.6-6.9 mmol/L) compared to NGT [19, 35-37, 40, 42, 43]. Seven studies have considered IGT defined by the 1999 WHO criteria of 2-h prandial glucose (2-h glucose) $7.8-11.0 \mathrm{mmol} / \mathrm{L}$ on the oral glucose tolerance test (OGTT) compared to NGT $[19,26,33,36,39,40,42,44]$. One study also considered a combined IFG-IGT group (defined by the $2003 \mathrm{ADA}$ and 1999 WHO criteria combined) compared to NGT [19]. Three studies including one population based and two hospital/university clinic based did not find differences in cardiac autonomic function in subjects with IGT defined by the 1999 WHO criteria compared to NGT. However, these were all of a small sample size below 200 patients and two of these studies had only used one test for CAN, the heart rate response to deep breathing (DB) $[2,45-47]$. This is a valid measurement of cardiac autonomic function but the use of more than one test is preferable for assessing CAN $[2,13,48]$. One study found that $25 \%$ of 268 people with IGT defined by the 1999 WHO criteria had an abnormal heart rate response to DB which might represent early CAN but did not include an NGT control group for comparison [49].

Data collected by the Cooperative Health Research in the Region of Augsburg (KORA S4) population-based survey of 1332 participants showed that pre-DM is linked to the development of CAN prior to the onset of T2DM [19]. The estimated prevalence of CAN in IFG was $8.1 \%$, and in IGT alone this was 5.9\%. Patients 
with both IFG and IGT had an $11.4 \%$ prevalence of CAN, similar to the $11.7 \%$ observed in those with newly diagnosed diabetes (n-DM). Patients with known diabetes (k-DM) had a $17.5 \%$ prevalence of CAN. All abnormal glucose regulation categories had a significantly greater prevalence of CAN (apart from isolated IGT) with $p<0.05$ compared to NGT where the prevalence was $4.5 \%$ [19]. This demonstrates that there is a continuum of increasing risk for CAN across abnormal glucose categories. This study also showed that other components of MetS, including an elevated BMI and hypertension, were associated with reduced HRV, a finding shared with two other population-based studies $[19,34,50]$. There is an inverse relationship between HRV and plasma glucose levels that applies to patients with pre-DM and diabetes, beginning with IFG [34].

A large Chinese population-based study ( $n=2092$, aged $30-80$ years) found a $24 \%$ prevalence of CAN in people with MetS. This was strikingly high, and close to the figure for patients with diabetes $(31.2 \%)$ [27, 50]. Obesity is associated with the development of CAN (in addition to IGT), where the prevalence of parasympathetic dysfunction is estimated to be about $25 \%$ [49]. There is limited published data on the prevalence of CAN in subjects with obesity alone (without pre-DM/ MetS). However, one small study estimated that early CAN defined as one abnormal or two borderline autonomic function tests of heart rate response was found in $22.5 \%$ of obese subjects with NGT [51]. Reduced HRV has also been demonstrated in obesity, in the absence of other cardiovascular risk factors or components of the MetS [52]. A systematic review of 14 studies in the literature has demonstrated that HRV is altered differently in men and women with MetS. A consistent reduction in HRV was demonstrated in women with MetS whilst results were inconsistent in men. These gender differences require further study and could be important when determining the effectiveness of interventions [53].

\section{PATHOGENESIS OF CAN}

Autonomic neuropathy (AN) including CAN has a multifactorial aetiology summarised in
Fig. 1. Age, BMI, waist circumference, hypertension, fasting glucose, 2-h postload glucose, and postprandial glucose all correlate with the development of abnormal autonomic indices including HRV in pre-DM $[2,40]$. These risk factors result in early CAN through the development of a sympathovagal imbalance with SNS predominance [54]. SNS predominance results from a combination of hyperinsulinaemia associated with MetS and PNS denervation. Insulin-driven SNS activation occurs via peripheral and central mechanisms, including stimulation of carotid chemoreceptors [2, 55]. PNS denervation of the vagal nerve fibres occurs early in CAN because the longer PNS nerve fibres are affected first because of the lengthdependent manner of the neuropathy [56]. SNS predominance may then result in further insulin resistance and hyperinsulinaemia in pre-DM [57]. Together, these effects lead to a reduction in HRV [58]. A greater resting heart rate and reduced HRV have been correlated with the risk of developing components of the MetS, and the subsequent risk of cardiovascular mortality [59]. Lifestyle interventions including dietary and exercise interventions to achieve weight loss could help to reverse the development of early CAN, by reducing insulin resistance and hyperinsulinaemia, leading to a reduction in SNS activation $[2,60]$. Later in the development of CAN, denervation of the SNS nerve fibres occurs commencing at the apex of the cardiac ventricles and progressing towards the base [61]. Reversibility is less likely as progression of CAN occurs [3].

Hyperglycaemia, caused by diabetes or in pre-DM states, also initiates multiple mechanisms including mitochondrial dysfunction and the formation of damaging reactive oxygen species which result in neuropathy of the autonomic nervous system (ANS) [60]. This contributes to the development of CAN in parallel to other microvascular complications [62].

The role of dyslipidaemia including raised triglycerides (TG) is well established in the development of microvascular complications including CAN $[13,63]$. A raised blood pressure (BP) has been demonstrated as a risk factor for CAN [62]. Indeed, the absence of hypertension has been suggested as a significant negative 


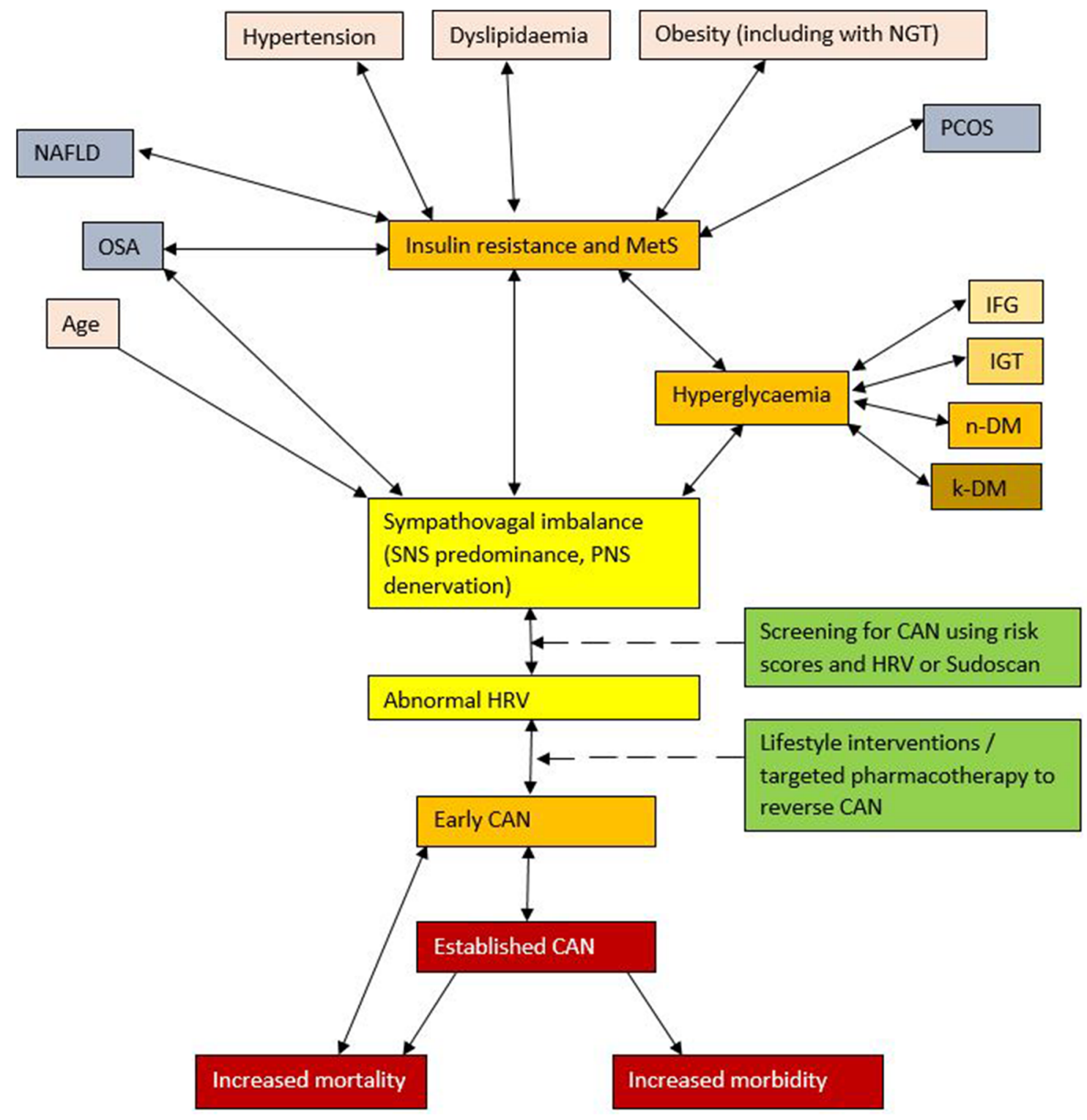

Fig. 1 The multifactorial aetiology of cardiac autonomic neuropathy (CAN). Multiple factors contribute to the development of CAN in pre-DM and MetS including age, obesity measured by BMI and WC, hypertension, dyslipidaemia and hyperglycaemia [2, 40]. Initially, sympathovagal imbalance develops with PNS denervation and SNS predominance $[1,9,54]$. Sympathovagal imbalance may result in insulin resistance and hyperinsulinaemia which drives further SNS activation in a vicious cycle [58]. This manifests as reduced HRV and early CAN [2]. Reduced HRV leads to a greater risk of developing MetS, CAN and the subsequent risk of cardiovascular mortality $[2,12,13,62,152,159]$. PCOS and NAFLD are associated with MetS and contribute to the increasing population of CAN $[88,96]$. OSA is associated with CAN via MetS and possibly an independent mechanism [82]. Screening for CAN at an early stage could allow lifestyle interventions and/or targeted pharmacotherapy to prevent or reverse CAN $[13,60]$. CAN cardiac autonomic neuropathy, HRV heart rate variability, IFG impaired fasting glucose, IGT impaired glucose tolerance, k-DM known diabetes mellitus, MetS metabolic syndrome, NAFLD non-alcoholic fatty liver disease, NGT normal glucose tolerance, n-DM newly detected diabetes mellitus, OSA obstructive sleep apnoea, PNS parasympathetic nervous system, PCOS polycystic ovary syndrome, SNS sympathetic nervous system 
predictive factor $(p=0.001)$ in a risk score proposed for CAN screening [19]. A study of patients with T2DM showed that the prevalence of hypertension was greater in those with CAN compared to those without $(57 \%$ vs $49 \%$ $p<0.001$ ) [64]. Central obesity with a raised diastolic blood pressure has also been associated with CAN [40]. Regression analyses in patients with pre-DM shows an elevated BMI as a risk factor for CAN in both European and Chinese populations $[19,27]$. Serum creatinine has been shown to correlate with CAN in patients with diabetes but the relationship has not been examined fully in pre-DM $[2,19]$.

\section{MORBIDITY AND MORTALITY ASSOCIATED WITH CAN}

In the setting of the MetS and pre-DM, the potential interactions of CAN with insulin resistance and other cardiovascular risk factors to increase cardiovascular mortality require further research [2]. Insulin resistance contributes to cardiovascular disease in pre-DM (relative risk 1.43 compared to those without insulin resistance), whilst CAN may drive increasing insulin resistance and MetS [65]. The Framingham Offspring Cohort showed that individuals with abnormal HRV indices had a greater risk of developing features of the MetS including hypertension, a raised BMI and dyslipidaemia over a 12-year period. They additionally had a greater risk of developing diabetes, cardiovascular disease and mortality over a 20-year period [59].

The KORA S4 survey demonstrated a statistically significant $(p<0.05)$ increase in all-cause and cardiovascular mortality in patients with NGT and reduced HRV, an index of CAN [19]. Individuals with HRV measured below the 5th centile of the normal population from three different HRV measures had an all-cause mortality of $16.9 \%$ (95\% confidence interval (CI) $9.8,26.5)$ compared to $7.2 \%$ (95\% CI 6.0, 8.5) for those with HRV measured at or above the 5th centile over a 7-year period [19]. This is of particular concern as CAN is associated with other features of the MetS including hypertension and raised BMI that may predate the development of hyperglycaemia [66]. In the same study there was a gradual increase in allcause mortality observed over 7 years through different stages of abnormal glucose regulation from IFG, to IFG-IGT combined, n-DM and $\mathrm{k}$-DM in parallel to an increasing prevalence of CAN [19].

CAN is an independent risk factor for increased cardiac arrhythmias, silent myocardial ischaemia, major cardiovascular events, myocardial dysfunction and cardiovascular mortality $[2,9,13]$. Importantly, increased risk is conveyed even at an asymptomatic stage [3]. Earlier studies have demonstrated a 5-year mortality of between $16 \%$ and $50 \%$ from the time of diagnosis of CAN in T1DM and T2DM [67]. This is higher than the corresponding 5 -year mortality for common cancers including prostate cancer and breast cancer (both about $10 \%$ 5-year mortality) in England and Wales $[68,69]$.

Population-based studies demonstrate that there are a higher proportion of deaths consistent with SCD in CAN $[9,60]$. This is postulated to be mediated via an increased risk of silent myocardial ischaemia and QT interval prolongation leading to cardiac arrest [31]. In patients with diabetes, Ewing et al. showed nearly 30 years ago that the resting QTc is correlated with the stage of development of CAN. The study also showed that the resting QTc was longest in individuals who died unexpectedly in follow-up, possibly as a result of cardiac arrhythmias [14].

HFpEF (previously termed diastolic heart failure) is associated with significantly increased mortality and could occur more quickly in patients with diabetes and CAN [70]. The parasympathetic denervation that occurs in the early stages of CAN with sympathetic tone predominance promotes metabolic changes in the heart including high myocardial catecholamine levels $[9,71]$. This increases myocardial oxygen demand, leading to myocardial hypertrophy and left ventricular remodelling [72]. Ultimately the resulting maladaptive cellular changes cause apoptosis and fibrosis which clinically presents as HFpEF $[72,73]$. 


\section{Role of ANS in Energy Homeostasis}

A complex homeostatic system is responsible for maintaining body weight, enabling individuals to maintain a stable body weight in the face of a changing environment [74].

This requires a complicated signalling system with both hormonal and neuronal components transmitting peripheral information from the gastrointestinal (GI) tract, and other organs such as adipose tissue to the central nervous system (CNS). However, there is a continuing obesity epidemic with excess consumption of readily available high fat and carbohydrate diet with low cost and associated poor nutrition $[75,76]$. Combined with a sedentary lifestyle, this provides a calorific excess causing weight gain in many individuals particularly associated with low socioeconomic status [77]. Elevated BMI is associated with CAN $[19,27]$. Autonomic neuropathy reduces the ability of the ANS to allow effective communication between the peripheral (including the GI tract) and CNS components of this homeostasis [78]. This could theoretically contribute to further weight gain, obesity and worsening autonomic function by reducing neuro-humoral stimuli following food intake, thus impairing satiety [74].

\section{ANS and Long-Term Regulation of Body Weight}

The ANS influences the longer-term regulation of body weight through changes in energy storage and expenditure, which is modulated in part by leptin [79]. The SNS increases energy expenditure through three postulated mechanisms: encouraging brown adipose tissue (BAT) thermogenesis, and positive inotropic and chronotropic effects on the cardiovascular system $[80,81]$. CAN, gastrointestinal and wider autonomic neuropathy may reduce the ability of the SNS to increase energy expenditure and thereby contribute to weight gain, although the exact mechanisms are not entirely clear [74]. Further research is required in the setting of preDM to establish if early autonomic dysfunction could lead to a predisposition for weight gain due to changes in energy expenditure.

\section{MetS, Obstructive Sleep Apnoea (OSA) and CAN}

OSA is a common co-morbidity in people with T2DM, because both OSA and T2DM are linked to a raised BMI and obesity sharing common pathophysiology. There might also be an independent association between the MetS and OSA, which is not yet fully understood and could be related to hyperglycaemia, independent of weight [82]. Upregulation of the carotid chemoreceptors in OSA due to episodes of chronic nocturnal hypoxia leads to SNS overactivity $[2,83]$. This contributes to ANS dysfunction in early CAN with additional insulindriven SNS activation observed in the hyperinsulinaemic states of MetS and pre-DM [57].

Episodes of apnoea occurring during OSA cause transient SNS activation, which represents a confounding factor when interpreting cardiovascular reflex tests of autonomic function $[84,85]$. This may reduce the specificity for diagnosing CAN in these patients. Improvements in ANS function were observed in patients with OSA who were compliant with continuous positive airways pressure (CPAP) including significant improvements in baroreceptor sensitivity $(p<0.04)$ [82]. This supports OSA contributing to CAN pathophysiology that is partially reversed by CPAP. This may represent a novel therapeutic strategy in early CAN in patients with additional cardiovascular risk factors $[82,86]$.

\section{Polycystic Ovary Syndrome (PCOS) and CAN}

PCOS is the most common endocrine disorder of reproductive aged women worldwide [87]. PCOS is associated with obesity measured by central adiposity and insulin resistance, which plays a key role in its pathogenesis [87, 88]. Obese women with PCOS have an increased risk of MetS including IGT (31-35\%) and T2DM (7.5-10\%) [88]. The large population of patients with PCOS could therefore contribute to an increasing prevalence of CAN because of the known links between MetS and CAN [60]. The hyperinsulinaemia of PCOS with MetS could 
drive the development of CAN [89]. A study of 31 newly diagnosed patients with PCOS demonstrated significant reductions in HRV and a SNS predominance compared to a control group of 30 age-matched participants [90]. These reductions in HRV could contribute to an increased cardiovascular risk in this young age group [91]. Metformin inhibits hepatic gluconeogenesis and is often used as a monotherapy in young women with PCOS owing to its beneficial effect of reducing serum androgens $[87,92,93]$. Studies are required to examine whether metformin leads to a beneficial improvement in HRV in patients with PCOS.

\section{Non-alcoholic Fatty Liver Disease (NAFLD) and CAN}

NAFLD is a major health problem in developed countries that may lead to liver cirrhosis and hepatocellular carcinoma $[94,95]$. NAFLD is associated with obesity, insulin resistance and MetS [94]. A recent study using magnetic resonance spectroscopy to define NAFLD as hepatic steatosis of greater than $5 \%$ in 46 participants demonstrated significant reductions in cardiac autonomic function measured by HRV compared with controls $(n=34)$ who had no cardiac, liver or metabolic disorders and consumed less than 20 grams of alcohol per day [96]. This study also showed significant reductions in HRV in 16 patients with dual aetiology fatty liver disease (DAFLD), who had hepatic steatosis of less than $5 \%$ and consumed more than 20 grams of alcohol per day compared to the control group [96].

\section{DIAGNOSTIC ASSESSMENT}

The cardiovascular reflex tests and spectral analysis of HRV used for the detection of CAN are summarised in Table 3. Early CAN may be entirely asymptomatic and detected only through abnormal cardiovascular reflex testing [13]. Approaches for assessing CAN in clinical practice involve assessing the patient's symptoms, any signs of CAN on clinical examination, cardiovascular reflex testing and ambulatory blood pressure monitoring (ABPM).
Symptoms of postural hypotension include dizziness on standing, presyncope and syncope $[3,13]$. The problem with relying on symptoms for diagnosis of CAN is that they correlate weakly with actual autonomic deficits and often appear late in CAN, at which point there is little reversibility of the disease $[9,97]$. Screening for CAN using cardiovascular reflex tests and HRV should be considered to diagnose CAN at an earlier stage where risk factor modification is possible and reversibility is more likely. Two studies have proposed screening scores which could help identify patients that could benefit from earlier diagnostic testing. One proposed score has suggested the use of resting heart rate, the presence/absence of hypertension, BMI and serum creatinine but acknowledges that further validation is required $[19,27]$.

Clinical examination signs suggesting the presence of CAN include a resting tachycardia, exercise intolerance, a postural blood pressure drop of at least $20 \mathrm{mmHg}$ in systolic blood pressure or in diastolic blood pressure of at least $10 \mathrm{mmHg}$ within $3 \mathrm{~min}$ of standing [1]. ABPM is a useful tool that can be offered to patients to help to demonstrate a loss of the normal BP circadian rhythm. This should help prompt formal testing for CAN with cardiovascular reflex tests [13].

Objective evidence of CAN is defined and assessed using standard bedside cardiovascular reflex tests and HRV [60]. The diagnosis of CAN should be based upon the results of a battery of tests rather than one result, as there is no superiority of any one test [1]. The cardiovascular reflex tests are considered the gold standard because they are reproducible, safe, sensitive, specific and correlate with peripheral neuropathy [13]. Different protocols of cardiovascular reflex testing can be used on the basis of the responses of the heart rate (measured by the R-R interval on an ECG) and blood pressure to a variety of stimuli [3]. Spectral analysis of HRV uses a 10-min continuous resting ECG recording, which should be at the start of the tests to avoid any bias. Advanced computer processing produces the power spectrum of HRV with there major peaks: a very low frequency (VLF) component representing the SNS division of autonomic function, the low 


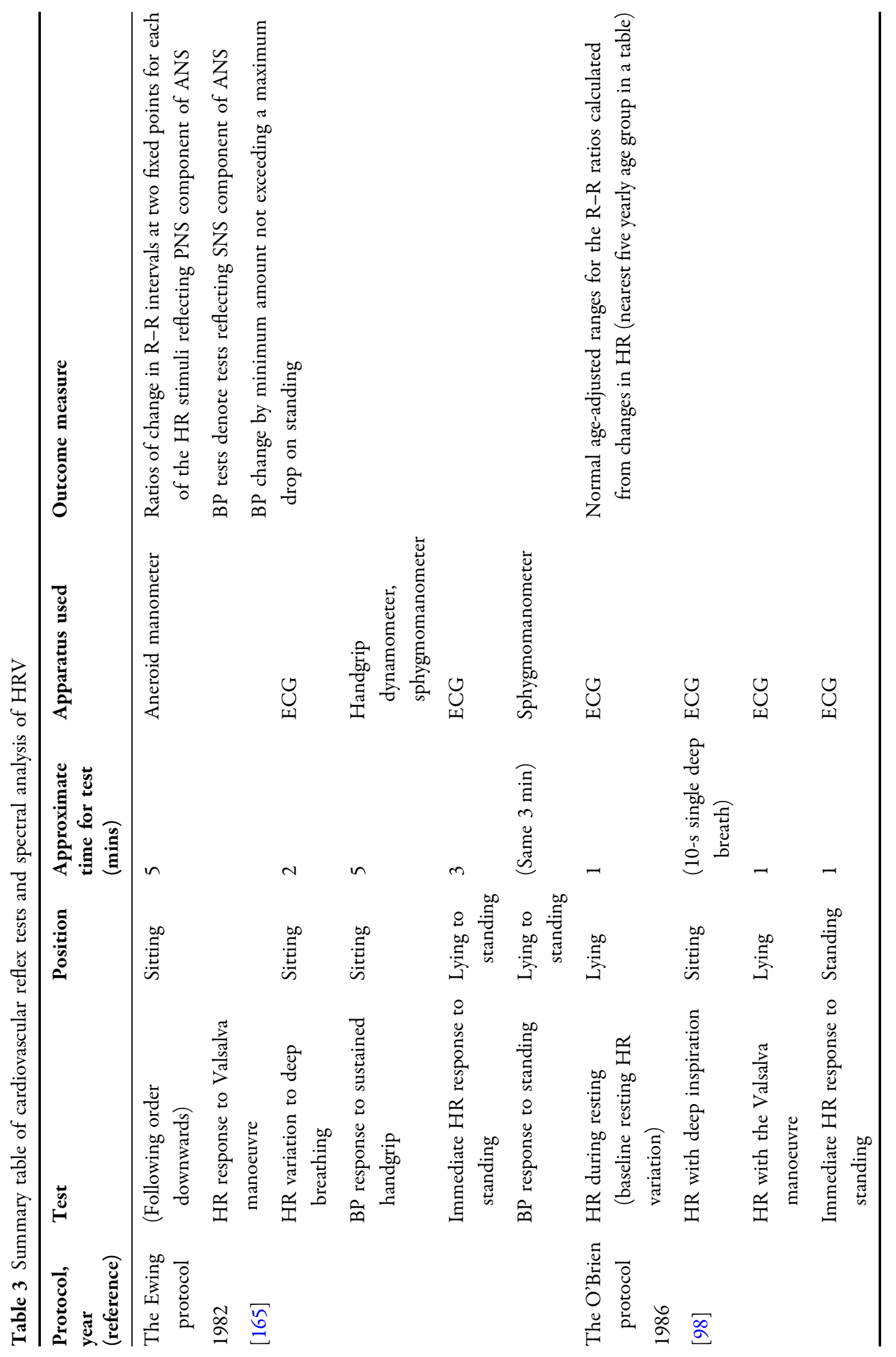




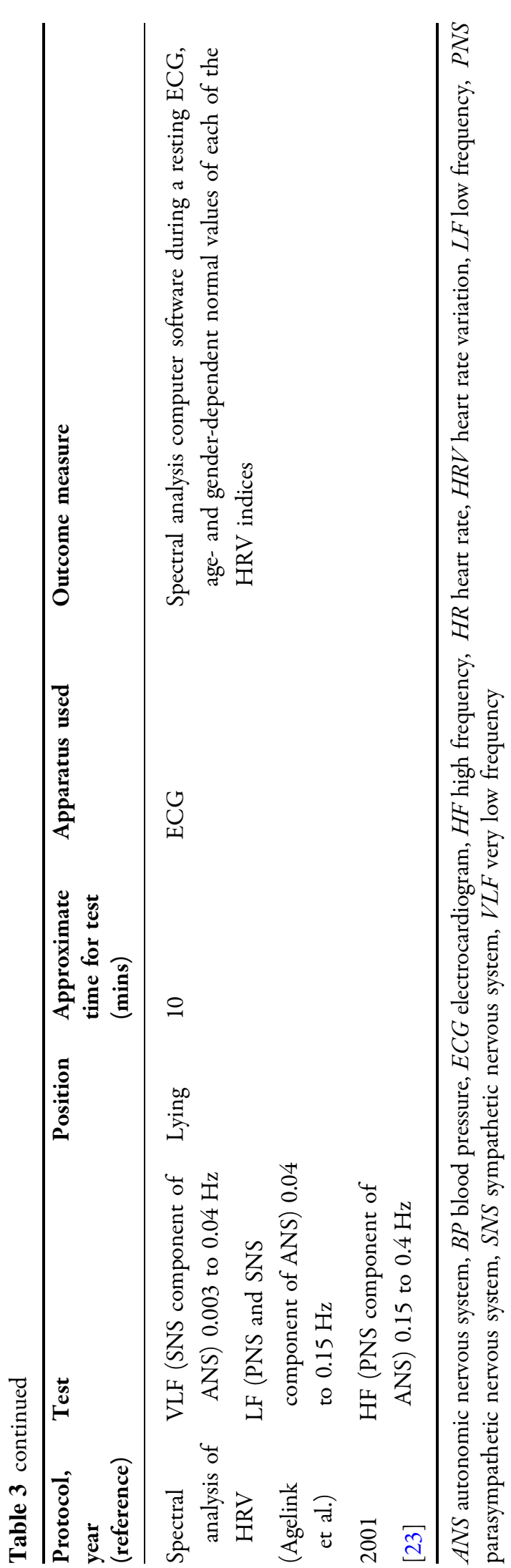

frequency (LF) band representing a combination of PNS and SNS function, and the high frequency (HF) band corresponding to PNS function [9]. Age- and sex-adjusted reference ranges allow for detection of abnormal indices [23].

\section{Classification of CAN}

The clinical presentations of CAN may be classified into three stages according to the number of abnormal investigations and the presence or absence of symptoms $[2,13,60]$. Progression of CAN is associated with an increasingly worse prognosis [13]:

1. During the subclinical stage or possible early CAN, there is decreased HRV or one abnormal cardiovascular reflex test result.

2. Definite confirmed CAN is the presence of two or more abnormal cardiovascular reflex test results and is often accompanied by a resting tachycardia.

3. Severe advanced CAN is the features of definite confirmed CAN plus orthostatic hypotension. This is often accompanied by evidence of cardiomyopathy with left ventricular dysfunction on echocardiography and silent myocardial ischaemia. Symptomatic CAN is severe advanced CAN with symptoms of exercise intolerance, palpitations and postural dizziness or presyncope.

\section{Confounding Factors to Consider When Interpreting Cardiovascular Reflex Test Results and HRV}

There are several confounding factors that need to be considered when interpreting the results of cardiovascular reflex test results and HRV indices. Age is adjusted using the age-adjusted normal range data $[23,98]$. The patient should be instructed to avoid consuming coffee, other caffeinated beverages, alcohol or smoking before testing because these may exert ANS effects causing false results [13]. Medications which could affect the functioning of the ANS including beta blockers should be stopped with sufficient time to be fully metabolised before 
testing wherever possible [99]. If possible, sympathomimetic drugs should be stopped for 24-48 $\mathrm{h}$ before testing, and anticholinergics for $48 \mathrm{~h}$ [100].

\section{Newer Potential Approaches to Diagnosis of CAN}

Novel techniques may allow earlier diagnosis and intervention for CAN $[2,101,102]$. The use of predictive risk scores for CAN could identify patients who would benefit from earlier testing $[19,103]$. Sudoscan uses sensitive electrodes for the hands and feet connected to modern computer software [104, 105]. A low voltage current is applied to measure sweat gland function based on sweat chloride concentrations through reverse iontophoresis and chronoamperometry [106]. A measurement of the electrochemical skin conductance (ESC) of the hands and feet is calculated. Both foot and hand ESC have a strong correlation with individual indices and composite scores of nerve conduction and CAN [107]. Sudoscan has been shown to correctly classify CAN measured by five standard cardiovascular reflex tests of autonomic function with a sensitivity of $65 \%$ and specificity of $80 \%$ $[107,108]$. This method is non-invasive and easy to perform within $5 \mathrm{~min}$ in a clinical setting [104]. Sudoscan could therefore be used as a screening tool for peripheral neuropathy and CAN during annual assessment in a busy diabetes clinic [104, 107]. Further prospective research in pre-DM and MetS is required to investigate if Sudoscan can predict the development of CAN [108].

The laser Doppler imaging FLARE (LDI FLARE) measures axon-mediated neurogenic vasodilatation using laser Doppler imaging in response to heating of the dorsal foot skin to $44{ }^{\circ} \mathrm{C}$ [109]. LDI FLARE is a known sensitive and specific non-invasive measure of early small fibre neuropathy in diabetes [110-112]. A study of patients with T1DM has closely correlated HRV with measures obtained using LDI FLARE and suggested that HRV may be used as a biomarker for peripheral neuropathy [112]. LDI FLARE has also been used for the detection of early small fibre peripheral neuropathy in patients with IGT [110]. Conversely, patients identified as having abnormal LDI FLARE measures in pre-DM or diabetes could be considered for early testing for CAN including HRV assessment. The main disadvantage of LDI FLARE is the longer time taken to perform it as the skin is heated for 20 min using a skin probe $[109,113]$.

Corneal confocal microscopy (CCM) is a non-invasive and repeatable imaging technique which has rapidly evolved from a research technique to a diagnostic tool for assessing all microstructures of the cornea including the subbasal nerve plexus $[114,115]$. This uses a confocal microscope which simultaneously illuminates, scans and reconstructs images from a single point of tissue to a high resolution and magnification [116, 117]. CCM measures corneal nerve parameters including corneal nerve fibre density [111]. It is able to diagnose peripheral neuropathy in patients with diabetes, and earlier in IGT [111, 118, 119]. CCM has also been closely correlated with cardiovascular reflex tests of autonomic function in patients with diabetes [102, 120]. This suggests that CCM could be a new tool for the diagnosis of CAN in pre-DM and diabetes with further research required to examine its diagnostic utility [2].

\section{MANAGEMENT OF CAN}

An early diagnosis of CAN should be established wherever possible because multifactorial and lifestyle interventions can then be implemented to prevent or reverse CAN [13]. As recommended in the American Diabetes Association (ADA) position statement for diabetic neuropathy, prevention of CAN is the best way of avoiding its adverse consequences [3]. Structured lifestyle intervention is recommended already for individuals with IFG-IGT combined as they are at high risk for developing T2DM, and this approach is likely to reduce CAN $[19,121]$.

\section{Dietary Interventions}

The use of two different low energy diets (a diet high in cereal fibre and coffee with no red meat compared to a diet high in red meat, low in fibre 
and free of coffee) have been compared for effects on cardiac autonomic function. Over an 8 -week intervention period in obese patients with T2DM, the use of either diet to achieve a median $1198 \mathrm{~kJ}$ daily reduction in total daily energy intake and associated average weight loss of $5-6 \mathrm{~kg}$ led to similar improvements in HRV with improved PNS function [122]. This suggests that the reduction in total daily energy intake and associated weight loss is beneficial for preventing CAN rather than the type of diet used [122]. An uncontrolled study of overweight and obese patients with T2DM has shown that an energy-restricted diet of 6-$7 \mathrm{MJ} /$ day over a 16-week period achieved an average reduction in body weight of $11.1 \pm \mathrm{SD}$ (standard deviation) $1.0 \mathrm{~kg}$. This was a $10 \%$ reduction in initial weight and was associated with improvements in components of MetS including blood pressure, total cholesterol, HDL cholesterol, LDL cholesterol, triglycerides and reduced insulin resistance. Additionally, there were significant increases in HRV at follow-up $(p \leq 0.03)$ and these beneficial improvements in cardiac autonomic function were associated with the reduction in weight assessed by BMI $(p<0.05)$ [123].

\section{Exercise Interventions}

Physical activity such as walking, moderate endurance and aerobic exercise have shown demonstrable improvements in the ECG measurements of cardiac autonomic function including HRV [62]. Significant improvements in HRV indices were demonstrated in patients with T2DM following an aerobic exercise training programme three times a week for 6 months. In this intervention study, the subgroup with definite CAN showed the greatest improvement in HRV with a $40 \%$ reduction in LF power $(p<0.05)$ compared to those without CAN [124]. This suggests that exercise training leads to reduced activation of the ANS which could represent a reversible component of early CAN. An earlier study of 19 previously sedentary men aged 45-68 years with no history of diabetes showed an improvement in HRV following a 30-week exercise training intervention.
This intervention consisted of walking or jogging three to four times per week for $30 \mathrm{~min}$ per session at $68-81 \%$ of heart rate reserve [125]. Importantly, not all studies have demonstrated significant improvements in HRV following exercise interventions. A separate study of 16 female patients with T2DM showed a trend towards improvements in HRV measures but none reached statistical significance following a combined aerobic and resistance exercise intervention performed three times per week. This was possibly due to the comparatively shorter intervention period used of 12 weeks [126]. However, an even shorter intervention period of 8 weeks did demonstrate improvements in HRV in a small number of participants (three men and nine women, aged $56.9 \pm \mathrm{SD}$ 7.0 years) with two or more MetS risk factors defined by the NCEP ATP III [127]. This study used an individualised exercise prescription and participants received remote monitoring of their blood pressure, physical activity and body weight via smartphone. This shows that the monitoring and support provided may be an important determinant of success when using exercise interventions [128].

\section{Combined Diet and Exercise Lifestyle Interventions}

Lifestyle modifications to achieve weight loss including a calorie-controlled diet with regular exercise are an essential component of preventing CAN in obese individuals [3]. This recommendation is supported by combined diet and exercise lifestyle interventional studies $[2,129,130]$.

The Diabetes Prevention Program (DPP) measured indexes of HRV in patients deemed at risk of diabetes including those with obesity and pre-DM [131]. This study showed significant improvements in these indexes with a decrease in resting heart rate and increase in HRV, reducing the risk of CAN, following a lifestyle intervention in patients with IFG or IGT. This lifestyle intervention was of greater benefit than the pharmacological use of metformin in reducing the risk of developing diabetes and CAN assessed by HRV [132]. The lifestyle 
intervention used in DPP recommended dietary measures aiming to lose $5-10 \%$ of initial body weight commencing with a 20-min education session addressing a healthy diet and lifestyle. This was combined with a goal of $30 \mathrm{~min}$ of activity including walking on at least 5 days per week and avoiding excessive alcohol intake [133].

A pilot study of 25 non-diabetic subjects with MetS failed to show an improvement in HRV measures of CAN after a 24-week lifestyle intervention of supervised aerobic exercise and a Mediterranean diet [134]. However, a recent systematic review of the available evidence from 14 human and six animal studies has examined the effect of diet or exercise interventions in pre-DM, the MetS and diabetes. This review has found lifestyle interventions are effective in the treatment and prevention of neuropathy including CAN [135]. This review acknowledges that data from randomised control trials are required to confirm these findings $[3,135]$.

\section{Bariatric Surgery}

The use of bariatric surgery to achieve weight loss in severely obese individuals with NGT and T2DM improves indices of HRV $[136,137]$. A small study of ten severely obese individuals who underwent bariatric surgery (compared to a control group of seven severely obese individuals who did not have surgery) showed that improvements in the mean $\mathrm{BMI} \pm$ standard deviation (SD) from $52.3 \pm 7.6 \mathrm{~kg} / \mathrm{m}^{2}$ at baseline to $37.7 \pm 5.3 \mathrm{~kg} / \mathrm{m}^{2}$ at follow-up were associated with significant increases in HRV frequency domain measures of high and low frequency power. These changes demonstrate improvements in PNS and SNS function following bariatric surgery [136]. A further study of 23 severely obese patients with NGT has also shown improvements in ANS function measured by cardiac and sympathetic baroreflex function following an initial 10\% weight loss achieved by a laparoscopic adjustable gastric band [74, 138]. This approach also led to significant improvements in systolic and diastolic blood pressure (reduced by $12 \mathrm{mmHg}$ and $5 \mathrm{mmHg}$ respectively), which are likely to be beneficial because hypertension is a known risk factor for CAN [138, 139]. Improvements in cardiac and autonomic function have recently been demonstrated using Sudoscan, time and frequency domain analysis of HRV following bariatric surgery in patients with T2DM [140]. This suggests that bariatric surgery may have a beneficial effect of preventing CAN in addition to achieving weight loss [74, 141]. However, in patients who are not well followed up after bariatric surgery, malabsorption-related vitamin $B_{12}$ deficiency could adversely affect the ANS by causing a neuropathy [142]. Oral or intramuscular supplementation of vitamin $B_{12}$ is recommended after malabsorptive bariatric surgery including the biliopancreatic diversion or the biliopancreatic diversion with duodenal switch [142, 143].

\section{Pharmacological Interventions}

Use of the insulin sensitizer metformin to decrease the rise in postprandial insulin concentrations could lead to a beneficial reduction in insulin-mediated SNS activation, helping to improve cardiac autonomic function [144]. Metformin has been shown to improve cardiac autonomic balance measured by HRV in overweight people with T2DM [145]. This could be beneficial for preventing CAN by reducing SNS predominance that is often seen in its early stages. Interestingly, this study related the beneficial improvements in HRV to a decrease in free fatty acid concentrations and insulin resistance observed in the metformin group $(n=60)$ which occurred independently of HbA1c [146]. This suggests that metformin could be beneficial for HRV parameters in preDM which should be examined in future studies [56].

Glucagon-like peptide 1 (GLP-1) analogues, which are known to improve cardiovascular outcomes in T2DM and have a beneficial effect on weight loss, could potentially reduce early CAN in pre-DM through reductions in BMI [147]. However, use of the GLP-1 analogue liraglutide caused increases in heart rate and reduced HRV in recent studies despite significant weight loss and improvements in 
metabolic parameters [148]. Therefore, further examination is required to assess whether the effect of GLP-1 analogues to reduce HRV negatively affects their potential weight loss benefit for the prevention CAN [147, 148].

The sodium/glucose cotransporter 2 (SGLT2) inhibitors inhibit the renal reabsorption of glucose by inhibiting sodium/glucose transport protein 2 . In addition to conveying improvements in glycaemic control, they have also been shown to have cardiovascular and renal protective effects irrespective of the reduction of blood glucose in patients with T2DM [149]. Chronic activation of the SNS occurs in T2DM. SGLT2 inhibitors might exert their beneficial effects in reducing cardiovascular risk and the progression of nephropathy in diabetes by reducing SNS overactivity [8, 150]. It is likely that complex mechanisms underly this benefit through changes in sodium balance with a reduction in circulating volume that may help to reset ANS balance. This might be clinically beneficial in patients with early CAN, although it should be noted that SGLT2 inhibitors can cause postural hypotension due to volume depletion and should be introduced with caution $[2,151,152]$.

The ALADIN studies examined whether the administration of alpha-lipoic acid, a scavenger of free radicals which could be neuroprotective in the context of hyperglycaemia and diabetes, was of benefit for neuropathic symptoms and deficits. Intravenous treatment with alphalipoic acid followed by 6 months of oral treatment was well tolerated and had a beneficial effect on neuropathic deficits, although there was no significant improvement in symptoms. Longer-term studies examining the potential benefits of alpha-lipoic acid over years were recommended, and these could include HRV parameters in future research [153].

\section{Control of Cardiovascular Risk Factors}

Measures to address modifiable cardiovascular risk factors alongside hyperglycaemia are essential [3, 13]. This could be particularly important in patients with IFG and IGT combined, as these have the greatest risk of progression to T2DM and their prevalence of CAN only differs from newly diagnosed T2DM by $0.3 \%[19,154]$. This includes the strict management of hypertension using antihypertensive agents [155]. In the UK, National Institute for Health and Care Excellence (NICE) guidance states that treatment with medication should be considered after lifestyle interventions for patients with diabetes with a BP of 140/80 mmHg or higher. Angiotensin-converting enzyme (ACE) inhibitors are the first-line drug of choice. If there is any evidence of microalbuminuria defined by the albumin creatinine ratio (ACR), nephropathy, neuropathy, retinopathy or cerebrovascular damage medication should be titrated to achieve a BP below $130 / 80 \mathrm{mmHg}$ [156]. Additionally, the treatment of dyslipidaemia persisting following lifestyle changes is recommended using lipid modification therapy including statins, with smoking cessation support for any patients with a history of smoking [13]. Optimising glucose control as early as possible in patients with diabetes is important to prevent or delay the onset of CAN [3]. Finding the optimal glucose control is a risk-benefit decision balanced against the risks of hypoglycaemia. A target glycated haemoglobin A1c (HbA1c) of 48-$58 \mathrm{mmol} / \mathrm{mol}$ is appropriate in the absence of other risk factors for cardiovascular disease $[155,156]$. Individualised targets are recommended whilst slightly higher glycaemia targets will be appropriate for older patients with risk factors for cardiovascular disease to avoid hypoglycaemia-potentiated cardiac events [157]. The STENO-2 trial of patients with T2DM used a targeted, long-term (average intervention time of over 7 years) approach to optimise the control of the cardiovascular risk factors including hyperglycaemia, hypertension and dyslipidaemia and achieved a $68 \%$ risk reduction for CAN progression [129].

\section{Pharmacotherapy for Symptom Control}

Midodrine, an alpha-1 adrenergic agonist is used in the UK and USA for the treatment of severe orthostatic hypotension due to ANS dysfunction when corrective factors have been 


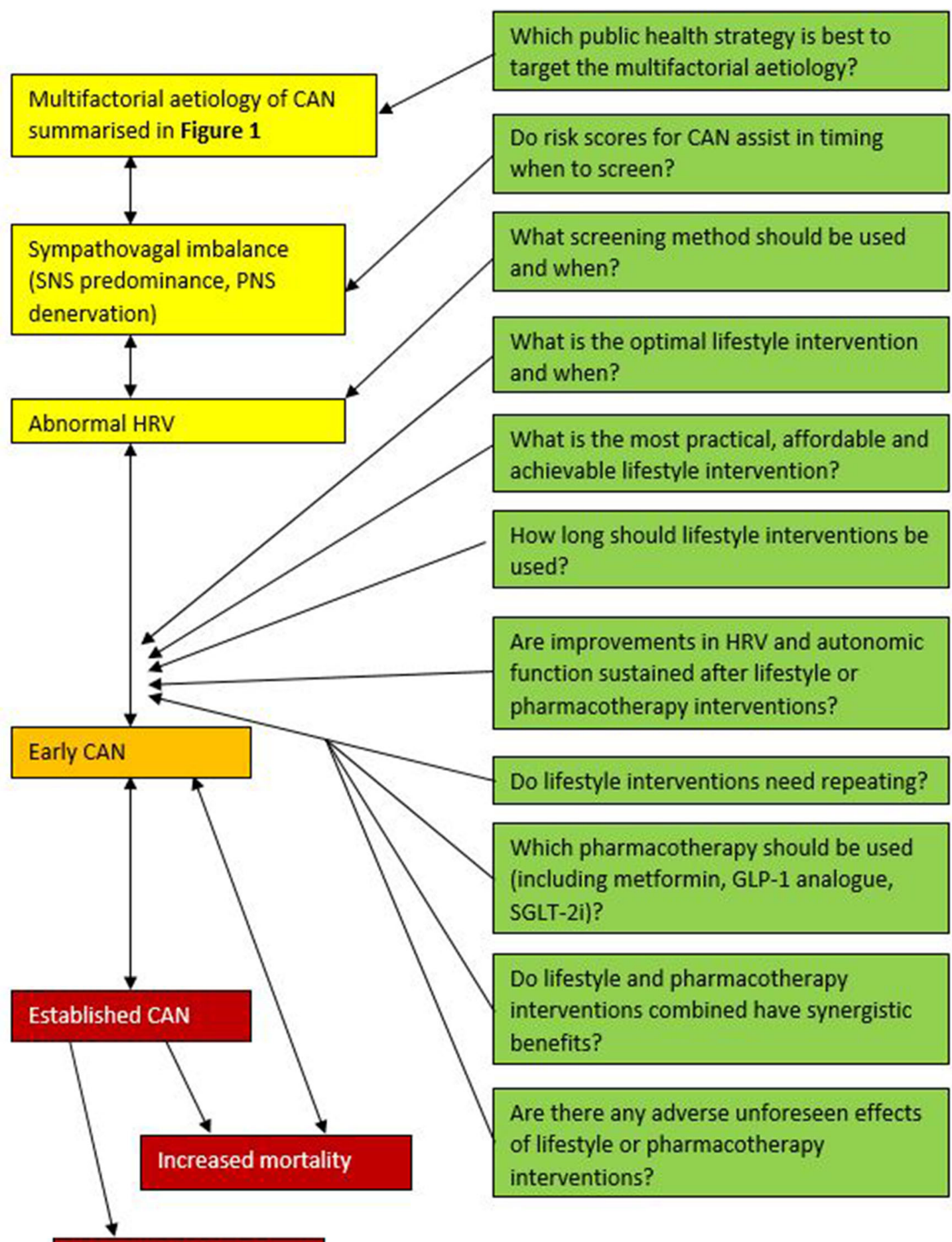

Increased morbidity 
4 Fig. 2 Future research questions for the management of CAN. Future research questions include the choice of lifestyle intervention used including the duration, frequency and intensity of exercise interventions and the degree of calorific restriction and choice of dietary interventions $[2,128]$. The practicalities of achieving these interventions consistently requires further examination, and whether interventions require repeating at a later date $[8,160]$. Observational studies to examine for any adverse effects of lifestyle or pharmacotherapy interventions are required, and to see if there is a synergistic benefit of the use of lifestyle interventions plus different choices of pharmacotherapy $[2,13,53,60]$. CAN cardiac autonomic neuropathy, GLP-1 glucagon-like peptide 1, HRV heart rate variability, PNS parasympathetic nervous system, SGLT2i sodium/glucose cotransporter 2 inhibitor, SNS sympathetic nervous system

ruled out and other forms of treatment are inadequate [158]. Fludrocortisone may also be beneficial in supplementing volume repletion in some patients [3]. A resting tachycardia associated with advanced CAN due to SNS predominance can be treated with cardioselective beta blockers including bisoprolol, which may have a cardioprotective effect in reducing the risk of cardiac arrhythmias [99].

\section{Management of Exercise Intolerance}

Exercise intolerance in CAN may be due to cardiovascular instability of worsening CAN, and the effects of orthostatic hypotension causing postural symptoms of dizziness and syncope. This reduces mobility causing physical deconditioning with decreased aerobic and anaerobic fitness [56]. To avoid the dangers of deconditioning, which exacerbates orthostatic intolerance with an increased risk of falls, regular physical activity and exercise should be encouraged [13, 159]. Ensuring patients are appropriately hydrated is central to the management of orthostatic hypotension and may be augmented by the use of midodrine or fludrocortisone [13].

\section{FUTURE THERAPIES AND NEW DIRECTIONS}

Larger randomised trials in patients with pre$\mathrm{DM}$ and the MetS comprising multifactorial and lifestyle interventions should be a focus of future research, to establish if effective prevention and treatment strategies for pre-DM also improve CAN $[2,60]$.

In particular, SNS predominance driven by hyperinsulinaemia might occur in early CAN and could represent a reversible component of ANS dysfunction amenable to lifestyle interventions or targeted pharmacotherapy (Fig. 1) $[12,13]$. A combined lifestyle and pharmacotherapy approach with the administration of metformin, GLP-1 analogues or SGLT2 inhibitors should be examined for a potential beneficial effect in reducing the incidence of CAN or reversing early CAN $[8,56,148]$.

Future research studies to address whether improvements in cardiac autonomic function are sustained with lifestyle interventions and pharmacotherapy during follow-up are required $[56,160]$. The use of risk scores for CAN to guide the timing of confirmatory tests for CAN and initiation of lifestyle or pharmacotherapy interventions requires exploration [19, 161]. Further research questions are summarised in Fig. 2.

\section{CONCLUSIONS}

CAN is a major cause of morbidity and cardiovascular mortality in patients with established diabetes. The aetiology of CAN is multifactorial. However, the association of CAN with an elevated BMI, obesity and the MetS offers the potential for lifestyle-based interventions to reduce its prevalence at a reversible stage. The early stages of CAN manifesting as ANS dysfunction on HRV testing begin to develop in people with pre-DM and MetS. Lifestyle interventions may improve CAN directly through modulation of the SNS and PNS innervation but also reverse the underlying pathophysiology of MetS, pre-DM and obesity. This therapeutic strategy should be targeted in CAN and remain the foundation of a holistic treatment pathway 
which also results in increased exercise tolerance and quality of life.

\section{ACKNOWLEDGEMENTS}

Funding. No funding or sponsorship was received for this study or publication of this article.

Authorship. All named authors meet the International Committee of Medical Journal Editors (ICMJE) criteria for authorship for this article, take responsibility for the integrity of the work as a whole, and have given their approval for this version to be published.

Disclosures. Scott Williams, Aikaterini Eleftheriadou, Uazman Alam, Daniel Cuthbertson, and John Wilding have nothing to disclose.

Compliance with Ethics Guidelines. This article is based on previously conducted studies and does not contain any studies with human participants or animals performed by any of the authors.

Open Access. This article is distributed under the terms of the Creative Commons Attribution-NonCommercial 4.0 International License (http://creativecommons.org/licenses/ by-nc/4.0/), which permits any noncommercial use, distribution, and reproduction in any medium, provided you give appropriate credit to the original author(s) and the source, provide a link to the Creative Commons license, and indicate if changes were made.

\section{REFERENCES}

1. Tesfaye S, Boulton AJM, Dyck PJ, et al. Diabetic neuropathies: update on definitions, diagnostic criteria, estimation of severity, and treatments. Diabetes Care. 2010;33(10):2285-93.

2. Spallone V. Update on the impact, diagnosis and management of cardiovascular autonomic neuropathy in diabetes: what is defined, what is new, and what is unmet. Diabet Metab J. 2019;43(1):3-30.

3. Pop-Busui R, Boulton AJM, Feldman EL, et al. Diabetic neuropathy: a position statement by the American Diabetes Association. Diabetes Care. 2017;40(1):136-54.

4. Mokdad AH, Serdula MK, Dietz WH, Bowman BA, Marks JS, Koplan JP. The spread of the obesity epidemic in the United States, 1991-1998. JAMA. 1999;282(16):1519-22.

5. Popkin BM, Doak CM. The obesity epidemic is a worldwide phenomenon. Nutr Rev. 1998;56(4):106-14.

6. Baum P, Petroff D, Classen J, Kiess W, Blüher S. Dysfunction of autonomic nervous system in childhood obesity: a cross-sectional study. PLoS One. 2013;8(1):e54546.

7. Raelene EM, Lenhard MJ. An overview of the effect of weight loss on cardiovascular autonomic function. Curr Diabetes Rev. 2007;3(3):204-11.

8. Vinik AI, Casellini C, Parson HK, Colberg SR, Nevoret ML. Cardiac autonomic neuropathy in diabetes: a predictor of cardiometabolic events. Front Neurosci. 2018;12:591.

9. Vinik AI, Maser RE, Mitchell BD, Freeman R. Diabetic autonomic neuropathy. Diabetes Care. 2003;26(5):1553-79.

10. Pop-Busui R. Cardiac autonomic neuropathy in diabetes: a clinical perspective. Diabetes Care. 2010;33(2):434-41.

11. Benichou T, Pereira B, Mermillod M, et al. Heart rate variability in type 2 diabetes mellitus: a systematic review and meta-analysis. PLoS One. 2018;13(4).

12. Vinik AI, Maser RE, Ziegler D. Autonomic imbalance: prophet of doom or scope for hope? Diabet Med. 2011;28(6):643-51.

13. Spallone V, Ziegler D, Freeman R, et al. Cardiovascular autonomic neuropathy in diabetes: clinical impact, assessment, diagnosis, and management. Diabetes Metab Res Rev. 2011;27(7):639-53.

14. Ewing DJ, Boland O, Neilson JM, Cho CG, Clarke BF. Autonomic neuropathy, QT interval lengthening, and unexpected deaths in male diabetic patients. Diabetologia. 1991;34(3):182-5.

15. Pop-Busui R, Evans GW, Gerstein HC, et al. Effects of cardiac autonomic dysfunction on mortality risk in the action to control cardiovascular risk in 
diabetes (ACCORD) trial. Diabetes Care. 2010;33(7):1578-84.

16. Bouthoorn S, Valstar GB, Gohar A, et al. The prevalence of left ventricular diastolic dysfunction and heart failure with preserved ejection fraction in men and women with type 2 diabetes: a systematic review and meta-analysis. Diab Vasc Dis Res. 2018;15(6):477-93.

17. Johansson I, Dahlström U, Edner $M$, Näsman $P$, Rydén L, Norhammar A. Type 2 diabetes and heart failure: characteristics and prognosis in preserved, mid-range and reduced ventricular function. Diab Vasc Dis Res. 2018;15(6):494-503.

18. Yadav RL, Yadav PK, Yadav LK, Agrawal K, Sah SK, Islam MN. Association between obesity and heart rate variability indices: an intuition toward cardiac autonomic alteration-a risk of CVD. Diabetes Metab Syndr Obes. 2017;10:57-64.

19. Ziegler D, Voss A, Rathmann W, et al. Increased prevalence of cardiac autonomic dysfunction at different degrees of glucose intolerance in the general population: the KORA S4 survey. Diabetologia. 2015;58(5):1118-28.

20. Eyre EL, Duncan MJ, Birch SL, Fisher JP. The influence of age and weight status on cardiac autonomic control in healthy children: a review. Auton Neurosci. $2014 ; 186: 8-21$.

21. Karayaylali I, San M, Kudaiberdieva G, et al. Heart rate variability, left ventricular functions, and cardiac autonomic neuropathy in patients undergoing chronic hemodialysis. Ren Fail. 2003;25(5):845-53.

22. Task Force of the European Society of Cardiology and the North American Society of Pacing and Electrophysiology. Heart rate variability: standards of measurement, physiological interpretation, and clinical use. Eur Heart J. 1996;17(3):354-81.

23. Agelink MW, Malessa R, Baumann B, et al. Standardized tests of heart rate variability: normal ranges obtained from 309 healthy humans, and effects of age, gender, and heart rate. Clin Auton Res. 2001;11(2):99-108.

24. Hostalek U. Global epidemiology of prediabetespresent and future perspectives. Clin Diabetes Endocrinol. 2019;5(1):5.

25. International Diabetes Federation. IDF Diabetes Atlas, 8th edn. Brussels: International Diabetes Federation; 2017. http://www.diabetesatlas.org. Accessed 1 June 2019.

26. Putz Z, Nemeth N, Istenes I, et al. Autonomic dysfunction and circadian blood pressure variations in people with impaired glucose tolerance. Diabet Med. 2013;30(3):358-62.

27. Ge X, Pan SM, Zeng F, Tang ZH, Wang YW. A simple Chinese risk score model for screening cardiovascular autonomic neuropathy. PLoS One. 2014;9(3).

28. WHO. Obesity and overweight fact sheet. Geneva: World Health Organization 2018. http://www.who. int/news-room/fact-sheets/detail/obesity-andoverweight. Accessed 1 June 2019.

29. Alberti KG, Zimmet PZ. Definition, diagnosis and classification of diabetes mellitus and its complications. Part 1: diagnosis and classification of diabetes mellitus provisional report of a WHO consultation. Diabet Med. 1998;15(7):539-53.

30. Alberti KG, Zimmet P, Shaw J. The metabolic syndrome- $\mathrm{a}$ new worldwide definition. Lancet. 2005;366(9491):1059-62.

31. Vinik AI, Ziegler D. Diabetic cardiovascular autonomic neuropathy. Circulation. 2007;115(3):387-97.

32. Vinik AI, Erbas T. Cardiovascular autonomic neuropathy: diagnosis and management. Curr Diab Rep. 2006;6(6):424-30.

33. Gerritsen J, Dekker JM, TenVoorde BJ, et al. Glucose tolerance and other determinants of cardiovascular autonomic function: the Hoorn Study. Diabetalogia. 2000;43(5):561-70.

34. Singh JP, Larson MG, O'Donnell CJ, et al. Association of hyperglycemia with reduced heart rate variability (the Framingham Heart Study). Am J Cardiol. 2000;86(3):309-12.

35. Schroeder EB, Chambless LE, Liao D, et al. Diabetes, glucose, insulin, and heart rate variability: the atherosclerosis risk in communities (ARIC) study. Diabetes Care. 2005;28(3):668-74.

36. Perciaccante A, Fiorentini A, Paris A, Serra P, Tubani L. Circadian rhythm of the autonomic nervous system in insulin resistant subjects with normoglycemia, impaired fasting glycemia, impaired glucose tolerance, type 2 diabetes mellitus. BMC Cardiovasc Disord. 2006;6:19.

37. Stein PK, Barzilay JI, Domitrovich PP, et al. The relationship of heart rate and heart rate variability to non-diabetic fasting glucose levels and the metabolic syndrome: the Cardiovascular Health Study. Diabet Med. 2007;24(8):855-63.

38. Wu JS, Yang YC, Lin TS, et al. Epidemiological evidence of altered cardiac autonomic function in subjects with impaired glucose tolerance but not 
isolated impaired fasting glucose. J Clin Endocrinol Metab. 2007;92(10):3885-9.

39. Tiftikcioglu BI, Bilgin S, Duksal T, Kose S, Zorlu Y. Autonomic neuropathy and endothelial dysfunction in patients with impaired glucose tolerance or type 2 diabetes mellitus. Medicine. 2016;95(14):1-6.

40. Dimova R, Tankova T, Guergueltcheva V, et al. Risk factors for autonomic and somatic nerve dysfunction in different stages of glucose tolerance. J Diabetes Complicat. 2017;31(3):537-43.

41. Report of the expert committee on the diagnosis and classification of diabetes mellitus. Diabetes Care. 1997;20(7):1183-97.

42. Wu JS, Yang YC, Lin TS, et al. Epidemiological evidence of altered cardiac autonomic function in subjects with impaired glucose tolerance but not isolated impaired fasting glucose. J Clin Endocrinol Metab. 2007;92(10):3885-9.

43. The Expert Committee on the Diagnosis and Classification of Diabetes Mellitus. Follow-up report on the diagnosis of diabetes mellitus. Diabetes Care. 2003;26(11):3160-7.

44. WHO. Definition, diagnosis and classification of diabetes mellitus and its complications: report of a WHO consultation. Part 1, Diagnosis and classification of diabetes mellitus. Geneva: World Health Organization 1999.

45. Annuzzi G, Rivellese A, Vaccaro O, Ferrante MR, Riccardi G, Mancini M. The relationship between blood glucose concentration and beat-to-beat variation in asymptomatic subjects. Acta Diabetol Lat. 1983;20(1):57-62.

46. Fujimoto WY, Leonetti DL, Kinyoun JL, et al. Prevalence of diabetes mellitus and impaired glucose tolerance among second-generation JapaneseAmerican men. Diabetes. 1987;36(6):721-9.

47. Isak B, Oflazoglu B, Tanridag T, Yitmen I, Us O. Evaluation of peripheral and autonomic neuropathy among patients with newly diagnosed impaired glucose tolerance. Diabetes/Metab Res Rev. 2008;24(7):563-9.

48. American Diabetes Association, American Academy of Neurology. Report and recommendations of the San Antonio conference on diabetic neuropathy. Diabetes Care. 1988;11(7):592-7.

49. Laitinen T, Lindström J, Eriksson J, et al. Cardiovascular autonomic dysfunction is associated with central obesity in persons with impaired glucose tolerance. Diabet Med. 2011;28(6):699-704.
50. Ge X, Pan S-M, Zeng F, Tang Z-H, Wang Y-W. A simple Chinese risk score model for screening cardiovascular autonomic neuropathy. PLoS One. 2014;9(3).

51. Akhter S, Begum N, Ferdousi S, Khan M. Autonomic neuropathy in obesity. J Bangladesh Soc Physiol. 2011;6(1):5-9.

52. Fidan-Yaylali G, Yaylali YT, Erdogan C,, et al. The association between central adiposity and autonomic dysfunction in obesity. Med Princ Pract. 2016;25(5):442-8.

53. Stuckey MI, Tulppo MP, Kiviniemi AM, Petrella RJ. Heart rate variability and the metabolic syndrome: a systematic review of the literature. Diabetes/Metab Res Rev. 2014;30(8):784-93.

54. Saito I, Maruyama K, Eguchi E, et al. Low heart rate variability and sympathetic dominance modifies the association between insulin resistance and metabolic syndrome-the Toon Health Study. Circ J. 2017;81(10):1447-53.

55. Greco C, Spallone V. Obstructive sleep apnoea syndrome and diabetes. Fortuitous association or interaction? Curr Diabetes Rev. 2015;12(2):129-55.

56. Serhiyenko VA, Serhiyenko AA. Cardiac autonomic neuropathy: risk factors, diagnosis and treatment. World J Diabetes. 2018;9(1):1-24.

57. Thorp AA, Schlaich MP. Relevance of sympathetic nervous system activation in obesity and metabolic syndrome. J Diabetes Res. 2015;2015:341583.

58. Svensson MK, Lindmark S, Wiklund U, et al. Alterations in heart rate variability during everyday life are linked to insulin resistance. A role of dominating sympathetic over parasympathetic nerve activity? Cardiovasc Diabetol. 2016;15(1):91.

59. Wulsin LR, Horn PS, Perry JL, Massaro JM, D'Agostino RB. Autonomic imbalance as a predictor of metabolic risks, cardiovascular disease, diabetes, and mortality. J Clin Endocrinol Metab. $2015 ; 100(6): 2443-8$.

60. Fisher VL, Tahrani AA. Cardiac autonomic neuropathy in patients with diabetes mellitus: current perspectives. Diabetes Metab Syndr Obes. 2017;10:419-34.

61. Pop-Busui R. What do we know and we do not know about cardiovascular autonomic neuropathy in diabetes. J Cardiovasc Transl Res. 2012;5(4):463-78.

62. Fisher VL, Tahrani AA. Cardiac autonomic neuropathy in patients with diabetes mellitus: current perspectives. Diabetes Metab Syndr Obes. 2017;10:419-34. 
63. Jaiswal M, Divers J, Urbina EM, et al. Cardiovascular autonomic neuropathy in adolescents and young adults with type 1 and type 2 diabetes: the SEARCH for diabetes in youth cohort study. Pediatr Diabetes. 2018;19(4):680-9.

64. Chung JO, Park SY, Cho DH, Chung DJ, Chung MY. Anemia, bilirubin, and cardiovascular autonomic neuropathy in patients with type 2 diabetes. Medicine (Baltimore). 2017;96(15).

65. Robins SJ, Rubins HB, Faas FH, et al. Insulin resistance and cardiovascular events with low HDL cholesterol: the Veterans Affairs HDL intervention trial (VA-HIT). Diabetes Care. 2003;26(5):1513-7.

66. Wulsin LR, Horn PS, Perry JL, Massaro JM, D'Agostino RB. Autonomic imbalance as a predictor of metabolic risks, cardiovascular disease, diabetes, and mortality. J Clin Endocrinol Metab. 2015;100(6):2443-8.

67. Balcıŏglu AS, Müderrisoğlu H. Diabetes and cardiac autonomic neuropathy: clinical manifestations, cardiovascular consequences, diagnosis and treatment. World J Diabetes. 2015;6(1):80-91.

68. Cancer Research UK. Prostate cancer survival 2016. https://www.cancerresearchuk.org/about-cancer/ prostate-cancer/survival. Accessed 1 June 2019.

69. Cancer Research UK. Breast cancer survival 2017. https://www.cancerresearchuk.org/about-cancer/ breast-cancer/survival. Accessed 1 June 2019.

70. Toledo C, Andrade DC, Lucero C, et al. Cardiac diastolic and autonomic dysfunction are aggravated by central chemoreflex activation in heart failure with preserved ejection fraction rats. J Physiol. 2017;595(8):2479-95.

71. Dimitropoulos G, Tahrani AA, Stevens MJ. Cardiac autonomic neuropathy in patients with diabetes mellitus. World J Diabetes. 2014;5(1):17-39.

72. Bissinger A. Cardiac autonomic neuropathy: why should cardiologists care about that? J Diabetes Res. 2017;2017:5374176.

73. Frustaci A, Kajstura J, Chimenti C, et al. Myocardial cell death in human diabetes. Circ Res. 2000;87(12):1123-32.

74. Guarino D, Nannipieri M, Iervasi G, Taddei S, Bruno RM. The role of the autonomic nervous system in the pathophysiology of obesity. Front Physiol. 2017;8:665.

75. Yumuk V, Tsigos C, Fried M, et al. European guidelines for obesity management in adults. Obes Facts. 2015;8(6):402-24.
76. Drewnowski A. Obesity, diets, and social inequalities. Nutr Rev. 2009;67(Suppl 1):S36-9.

77. Drewnowski A, Specter SE. Poverty and obesity: the role of energy density and energy costs. Am J Clin Nutr. 2004;79(1):6-16.

78. Dockray GJ. Gastrointestinal hormones and the dialogue between gut and brain. J Physiol. 2014;592(Pt 14):2927-41.

79. Pandit R, Beerens S, Adan RAH. Role of leptin in energy expenditure: the hypothalamic perspective. Am J Physiol Regul Integr Comp Physiol. 2017;312(6):R938-47.

80. Saris WH. Effects of energy restriction and exercise on the sympathetic nervous system. Int J Obes Relat Metab Disord. 1995;19(Suppl 7):S17-23.

81. Contreras C, Nogueiras R, Diéguez C, Rahmouni K, López M. Traveling from the hypothalamus to the adipose tissue: the thermogenic pathway. Redox Biol. 2017;12:854-63.

82. Coughlin SR, Mawdsley L, Mugarza JA, Wilding JP, Calverley PM. Cardiovascular and metabolic effects of CPAP in obese males with OSA. Eur Respir J. 2007;29(4):720-7.

83. Greco C, Spallone V. Obstructive sleep apnoea syndrome and diabetes. Fortuitous association or interaction? Curr Diabetes Rev. 2016;12(2):129-55.

84. Jo JA, Blasi A, Valladares E, Juarez R, Baydur A, Khoo MC. Model-based assessment of autonomic control in obstructive sleep apnea syndrome during sleep. Am J Respir Crit Care Med. 2003;167(2):128-36.

85. Tobaldini E, Nobili L, Strada S, Casali K, Braghiroli A, Montano N. Heart rate variability in normal and pathological sleep. Front Physiol. 2013;4(294).

86. Seetho IW, Asher R, Parker RJ, et al. Effect of CPAP on arterial stiffness in severely obese patients with obstructive sleep apnoea. Sleep Breath. 2015;19(4):1155-65.

87. Goodman NF, Cobin RH, Futterweit W, Glueck JS, Legro RS, Carmina E. American Association of Clinical Endocrinologists, American College of Endocrinology, and Androgen Excess and PCOS Society disease state clinical review: guide to the best practices in the evaluation and treatment of polycystic ovary syndrome-part 1 . Endocr Pract. 2015;21(11):1291-300.

88. Goodman NF, Cobin RH, Futterweit W, Glueck JS, Legro RS, Carmina E. American Association of Clinical Endocrinologists, American College of Endocrinology, and Androgen Excess and PCOS Society disease state clinical review: guide to the 
best practices in the evaluation and treatment of polycystic ovary syndrome-part 2 . Endocr Pract. 2015;21(12):1415-26.

89. Domenico K, Wiltgen D, Nickel F, Magalhães J, Moraes R, Spritzer P. Cardiac autonomic modulation in polycystic ovary syndrome: does the phenotype matter? Fertil Steril. 2012;99.

90. Saranya K, Pal GK, Habeebullah S, Pal P. Assessment of cardiovascular autonomic function in patients with polycystic ovary syndrome. J Obst Gynaecol Res. 2014;40(1):192-9.

91. Kuppusamy S, Pal GK, Habeebullah S, Ananthanarayanan $\mathrm{PH}, \mathrm{Pal} \mathrm{P}$. Association of sympathovagal imbalance with cardiovascular risks in patients with polycystic ovary syndrome. Endocr Res. 2015;40(1):37-43.

92. Johnson NP. Metformin use in women with polycystic ovary syndrome. Ann Transl Med. 2014;2(6):56.

93. Kim YD, Park K-G, Lee Y-S, et al. Metformin inhibits hepatic gluconeogenesis through AMP-activated protein kinase-dependent regulation of the orphan nuclear receptor SHP. Diabetes. 2008;57(2):306-14.

94. Yang KC, Hung H-F, Lu C-W, Chang H-H, Lee L-T, Huang K-C. Association of non-alcoholic fatty liver disease with metabolic syndrome independently of central obesity and insulin resistance. Sci Rep. 2016;6:27034.

95. Zhang X. NAFLD related-HCC: the relationship with metabolic disorders. Adv Exp Med Biol. 2018;1061:55-62.

96. Houghton D, Zalewski P, Hallsworth K, et al. The degree of hepatic steatosis associates with impaired cardiac and autonomic function. J Hepatol. 2019;70(6):1203-13.

97. Azmi S, Petropoulos I, Ferdousi M, Ponirakis G, Alam U, Malik R. An update on the diagnosis and treatment of diabetic somatic and autonomic neuropathy. F1000Res. 2019;8:186.

98. O'Brien IA, O'Hare P, Corrall RJ. Heart rate variability in healthy subjects: effect of age and the derivation of normal ranges for tests of autonomic function. Br Heart J. 1986;55(4):348-54.

99. Spallone V, Bellavere F, Scionti L, et al. Recommendations for the use of cardiovascular tests in diagnosing diabetic autonomic neuropathy. Nutr Metab Cardiovasc Dis. 2011;21(1):69-78.

100. Zygmunt A, Stanczyk J. Methods of evaluation of autonomic nervous system function. Arch Med Sci AMS. 2010;6(1):11-8.
101. Vinik AI, Nevoret M, Casellini C. The new age of sudomotor function testing: a sensitive and specific biomarker for diagnosis, estimation of severity, monitoring progression and regression in response to intervention. Front Endocrinol. 2015;6:94.

102. Tavakoli M, Begum P, McLaughlin J, Malik RA. Corneal confocal microscopy for the diagnosis of diabetic autonomic neuropathy. Muscle Nerve. 2015;52(3):363-70.

103. Yuan T, Li J, Fu Y, et al. A cardiac risk score based on sudomotor function to evaluate cardiovascular autonomic neuropathy in asymptomatic Chinese patients with diabetes mellitus. PLoS One. 2018;13(10).

104. Casellini CM, Parson HK, Richardson MS, Nevoret ML, Vinik AI. Sudoscan, a noninvasive tool for detecting diabetic small fiber neuropathy and autonomic dysfunction. Diabetes Technol Ther. 2013;15(11):948-53.

105. Vinik AI, Smith AG, Singleton JR, et al. Normative values for electrochemical skin conductances and impact of ethnicity on quantitative assessment of sudomotor function. Diabetes Technol Ther. 2016;18(6):391-8.

106. Mao F, Liu S, Qiao X, et al. Sudoscan is an effective screening method for asymptomatic diabetic neuropathy in Chinese type 2 diabetes mellitus patients. J Diabetes Investig. 2017;8(3):363-8.

107. Selvarajah D, Cash T, Davies J, et al. SUDOSCAN: a simple, rapid, and objective method with potential for screening for diabetic peripheral neuropathy. PLoS One. 2015;10(10).

108. Ziemssen T, Siepmann T. The investigation of the cardiovascular and sudomotor autonomic nervous system-a review. Front Neurol. 2019;10:53.

109. Krishnan STM, Rayman G. The LDIflare: a novel test of C-fiber function demonstrates early neuropathy in type 2 diabetes. Diabetes Care. 2004;27(12):29305 .

110. Green AQ, Krishnan S, Finucane FM, Rayman G. Altered C-fiber function as an indicator of early peripheral neuropathy in individuals with impaired glucose tolerance. Diabetes Care. 2010;33(1):174-6.

111. Azmi S, Ferdousi M, Petropoulos IN, et al. Corneal confocal microscopy identifies small-fiber neuropathy in subjects with impaired glucose tolerance who develop type 2 diabetes. Diabetes Care. 2015;38(8):1502-8.

112. Orlov S, Bril V, Orszag A, Perkins BA. Heart rate variability and sensorimotor polyneuropathy in type 1 diabetes. Diabetes Care. 2012;35(4):809-16. 
113. Abraham A, Alabdali M, Alsulaiman A, et al. Laser doppler flare imaging and quantitative thermal thresholds testing performance in small and mixed fiber neuropathies. PLoS One. 2016;11(11).

114. Tavakoli M, Petropoulos IN, Malik RA. Corneal confocal microscopy to assess diabetic neuropathy: an eye on the foot. J Diabetes Sci Technol. 2013;7(5):1179-89.

115. Petropoulos IN, Manzoor T, Morgan P, et al. Repeatability of in vivo corneal confocal microscopy to quantify corneal nerve morphology. Cornea. 2013;32(5):e83-9.

116. Tavakoli M, Hossain P, Malik RA. Clinical applications of corneal confocal microscopy. Clin Ophthalmol. 2008;2(2):435-45.

117. Papanas N, Ziegler D. Corneal confocal microscopy: recent progress in the evaluation of diabetic neuropathy. J Diabetes Investig. 2015;6(4):381-9.

118. Alam U, Jeziorska M, Petropoulos IN, et al. Diagnostic utility of corneal confocal microscopy and intra-epidermal nerve fibre density in diabetic neuropathy. PLoS One. 2017;12(7):e0180175.

119. Asghar O, Petropoulos IN, Alam U, et al. Corneal confocal microscopy detects neuropathy in subjects with impaired glucose tolerance. Diabetes Care. 2014;37(9):2643-6.

120. Maddaloni E, Sabatino F, Del Toro R, et al. In vivo corneal confocal microscopy as a novel non-invasive tool to investigate cardiac autonomic neuropathy in type 1 diabetes. Diabet Med. 2015;32(2):262-6.

121. Gregg EW, Boyle JP, Thompson TJ, Barker LE, Albright AL, Williamson DF. Modeling the impact of prevention policies on future diabetes prevalence in the United States: 2010-2030. Popul Health Metr. 2013;11(1):18.

122. Ziegler D, Strom A, Nowotny B, et al. Effect of lowenergy diets differing in fiber, red meat, and coffee intake on cardiac autonomic function in obese individuals with type 2 diabetes. Diabetes Care. 2015;38(9):1750-7.

123. Sjoberg N, Brinkworth GD, Wycherley TP, Noakes M, Saint DA. Moderate weight loss improves heart rate variability in overweight and obese adults with type 2 diabetes. J Appl Physiol. 2011;110(4):1060-4.

124. Pagkalos M, Koutlianos N, Kouidi E, Pagkalos E, Mandroukas K, Deligiannis A. Heart rate variability modifications following exercise training in type 2 diabetic patients with definite cardiac autonomic neuropathy. Br J Sports Med. 2008;42(1):47-54.
125. Seals DR, Chase PB. Influence of physical training on heart rate variability and baroreflex circulatory control. J Appl Physiol. 1989;66(4):1886-95.

126. Kang S-J, Ko K-J, Baek U-H. Effects of 12 weeks combined aerobic and resistance exercise on heart rate variability in type 2 diabetes mellitus patients. J Phys Ther Sci. 2016;28(7):2088-93.

127. Third Report of the National Cholesterol Education Program (NCEP) Expert panel on detection, evaluation, and treatment of high blood cholesterol in adults (adult treatment panel III) final report. Circulation. 2002;106(25):3143-421.

128. Stuckey MI, Kiviniemi AM, Petrella RJ. Diabetes and technology for increased activity study: the effects of exercise and technology on heart rate variability and metabolic syndrome risk factors. Front Endocrinol. 2013;4:121.

129. Gæde P, Vedel P, Larsen N, Jensen GVH, Parving $\mathrm{H}-\mathrm{H}$, Pedersen O. Multifactorial intervention and cardiovascular disease in patients with type 2 diabetes. New Engl J Med. 2003;348(5):383-93.

130. Gæde P, Lund-Andersen $\mathrm{H}$, Parving $\mathrm{H}-\mathrm{H}$, Pedersen O. Effect of a multifactorial intervention on mortality in type 2 diabetes. New Engl J Med. 2008;358(6):580-91.

131. The Diabetes Prevention Program (DPP). Description of lifestyle intervention. Diabetes Care. 2002;25(12):2165-71.

132. Carnethon MR, Prineas RJ, Temprosa M, Zhang ZM, Uwaifo G, Molitch ME. The association among autonomic nervous system function, incident diabetes, and intervention arm in the Diabetes Prevention Program. Diabetes Care. 2006;29(4):914-9.

133. Diabetes Prevention Program. Design and methods for a clinical trial in the prevention of type 2 diabetes. Diabetes Care. 1999;22(4):623-34.

134. Pennathur S, Jaiswal M, Vivekanandan-Giri A, et al. Structured lifestyle intervention in patients with the metabolic syndrome mitigates oxidative stress but fails to improve measures of cardiovascular autonomic neuropathy. J Diabetes Complicat. 2017;31(9):1437-43.

135. Zilliox LA, Russell JW. Physical activity and dietary interventions in diabetic neuropathy: a systematic review. Clin Auton Res. 2019;29(4):443-55.

136. Nault I, Nadreau E, Paquet C, et al. Impact of bariatric surgery-induced weight loss on heart rate variability. Metabolism. 2007;56(10):1425-30. 
137. Lips MA, de Groot GH, De Kam M, et al. Autonomic nervous system activity in diabetic and healthy obese female subjects and the effect of distinct weight loss strategies. Eur J Endocrinol. 2013;169(4):383-90.

138. Lambert EA, Rice T, Eikelis N, et al. Sympathetic activity and markers of cardiovascular risk in nondiabetic severely obese patients: the effect of the initial 10\% weight loss. Am J Hypertens. 2014;27(10):1308-15.

139. Xue Y, Lv Y, Tang Z, Dong J. Analysis of a screening system for diabetic cardiovascular autonomic neuropathy in China. Med Sci Monit. 2017;23:5354-62.

140. Casellini CM, Parson HK, Hodges K, et al. Bariatric surgery restores cardiac and sudomotor autonomic C-fiber dysfunction towards normal in obese subjects with type 2 diabetes. PLoS One. 2016;11(5).

141. Ashrafian H, le Roux Carel W, Darzi A, Athanasiou T. Effects of bariatric surgery on cardiovascular function. Circulation. 2008;118(20):2091-102.

142. Lupoli R, Lembo E, Saldalamacchia G, Avola CK, Angrisani L, Capaldo B. Bariatric surgery and longterm nutritional issues. World $\mathrm{J}$ Diabetes. 2017;8(11):464-74.

143. Fujioka K. Follow-up of nutritional and metabolic problems after bariatric surgery. Diabetes Care. $2005 ; 28(2): 481-4$.

144. Kern W, Peters A, Born J, Fehm HL, Schultes B. Changes in blood pressure and plasma catecholamine levels during prolonged hyperinsulinemia. Metabolism. 2005;54(3):391-6.

145. Miles JM, Rule AD, Borlaug BA. Use of metformin in diseases of aging. Curr Diab Rep. 2014;14(6):490.

146. Manzella D, Grella R, Esposito K, Giugliano D, Barbagallo M, Paolisso G. Blood pressure and cardiac autonomic nervous system in obese type 2 diabetic patients: effect of metformin administration. Am J Hypertens. 2004;17(3):223-7.

147. Álvarez-Villalobos NA, Treviño-Alvarez AM, González-González JG. Liraglutide and cardiovascular outcomes in type 2 diabetes. New Engl J Med. 2016;375(18):1798-9.

148. Kumarathurai P, Anholm C, Larsen BS, et al. Effects of liraglutide on heart rate and heart rate variability: a randomized, double-blind, placebo-controlled crossover study. Diabetes Care. 2017;40(1):117-24.

149. Zinman B, Wanner C, Lachin JM, et al. Empagliflozin, cardiovascular outcomes, and mortality in type 2 diabetes. New Engl J Med. 2015;373(22):2117-28.
150. Matthews V, Elliot R, Rudnicka C, Hricova J, Herat $\mathrm{L}$, Schlaich M. Role of the sympathetic nervous system in regulation of the sodium glucose cotransporter. J Hypertens. 2017;35(10):2059-68.

151. Sano M. A new class of drugs for heart failure: SGLT2 inhibitors reduce sympathetic overactivity. J Cardiol. 2018;71(5):471-6.

152. Vinik AI, Casellini C, Parson HK, Colberg SR, Nevoret ML. Cardiac autonomic neuropathy in diabetes: a predictor of cardiometabolic events. Front Neurosci. 2018;12.

153. Ziegler D, Hanefeld M, Ruhnau KJ, et al. Treatment of symptomatic diabetic polyneuropathy with the antioxidant alpha-lipoic acid: a 7-month multicenter randomized controlled trial (ALADIN III Study). ALADIN III Study Group. Alpha-lipoic acid in diabetic neuropathy. Diabetes Care. 1999;22(8):1296-301.

154. Morris DH, Khunti K, Achana F, et al. Progression rates from HbA1c $6.0-6.4 \%$ and other prediabetes definitions to type 2 diabetes: a meta-analysis. Diabetologia. 2013;56(7):1489-93.

155. Piepoli MF, Hoes AW, Agewall S, et al. 2016 European guidelines on cardiovascular disease prevention in clinical practice: the Sixth Joint Task Force of the European Society of Cardiology and Other Societies on Cardiovascular Disease Prevention in Clinical Practice (constituted by representatives of 10 societies and by invited experts)Developed with the special contribution of the European Association for Cardiovascular Prevention \& Rehabilitation (EACPR). Eur Heart J. 2016;37(29):2315-81.

156. Home P, Mant J, Diaz J, Turner C. Management of type 2 diabetes: summary of updated NICE guidance. BMJ. 2008;336(7656):1306-8.

157. Action to Control Cardiovascular Risk in Diabetes Study Group, Gerstein HC, Miller ME, et al. Effects of intensive glucose lowering in type 2 diabetes. New Engl J Med. 2008;358(24):2545-59.

158. Parsaik AK, Singh B, Altayar O, et al. Midodrine for orthostatic hypotension: a systematic review and meta-analysis of clinical trials. J Gen Intern Med. 2013;28(11):1496-503.

159. Pop-Busui R, Boulton AJM, Feldman EL, et al. Diabetic neuropathy: a position statement by the American Diabetes Association. Diabetes Care. 2017;40(1):136-54

160. Serhiyenko VA, Serhiyenko AA. Diabetic cardiac autonomic neuropathy: do we have any treatment perspectives? World J Diabetes. 2015;6(2):245-58. 
161. Zhu L, Zhao X, Zeng P, et al. Study on autonomic dysfunction and metabolic syndrome in Chinese patients. J Diabetes Investig. 2016;7(6):901-7.

162. Classification and Diagnosis of Diabetes. Standards of medical care in diabetes-2018. Diabetes Care. 2018;41(Suppl 1):S13-27.

163. Alberti KGMM, Eckel Robert H, Grundy Scott M, et al. Harmonizing the metabolic syndrome. Circulation. 2009;120(16):1640-5.
164. Misra A. Ethnic-specific criteria for classification of body mass index: a perspective for Asian Indians and American Diabetes Association position statement. Diabetes Technol Ther. 2015;17(9):667-71.

165. Ewing DJ, Clarke BF. Diagnosis and management of diabetic autonomic neuropathy. $\mathrm{Br}$ Med J. 1982;285(6346):916-8. 